\title{
Numerical Modelling of the No-Core-Melt Passive Safety Feature in the Generation IV Canadian SCWR
}

\author{
by \\ Graeme Schmidt \\ A thesis submitted to \\ the Faculty of Graduate and Postdoctoral Affairs \\ in partial fulfilment of \\ the requirements for the degree of \\ Master of Applied Science \\ in \\ Aerospace Engineering
}

Ottawa-Carleton Institute for Mechanical and Aerospace Engineering

Department of Mechanical and Aerospace Engineering

Carleton University

Ottawa, Ontario, Canada

September 2014

Copyright (C)

2014 - Graeme Schmidt 
The undersigned recommend to

the Faculty of Graduate and Postdoctural Affairs

acceptance of the thesis

\title{
Numerical Modelling of the No-Core-Melt Passive Safety Feature in the Generation IV Canadian SCWR
}

\author{
Submitted by Graeme Schmidt \\ in partial fulfilment of the requirements for the degree of \\ Master of Applied Science
}

Dr. John A. Goldak, Supervisor

Dr. Tarik Kaya, Co-Supervisor

Dr. Metin Yaras, Department Chair

Carleton University

2014 


\section{Abstract}

Heat transfer through a typical fuel channel in a Generation IV Canadian Supercritical Water Reactor was modelled numerically using Finite Element Method software. With the objective of limiting the fuel cladding to sub-melting temperatures during a Loss of Coolant Accident, it was found that two distinct fuel channel designs both attained maximum cladding surface temperatures of $\mathrm{T}=1,120^{\circ} \mathrm{C}$; a result that compared favourably with the $1,450{ }^{\circ} \mathrm{C}$ melting point of the stainless steel cladding. However, given the similar temperatures yielded by the reference and alternate fuel channel designs, it was deemed necessary to devise another metric for identifying the better performing variant. In this vein, the ratios of LOCA to normal operation thermal fluxes were computed and it was observed that the reference configuration performed best by limiting losses in normal operation while also permitting sufficient heat rejection to the moderator during the LOCA. 


\section{Acknowledgments}

I would like to extend my gratitude to my supervisors, Dr. John Goldak and Dr. Tarik Kaya of Carleton University, as well as Dr. Metin Yetisir of AECL for the wisdom and technical acumen which they were so kind to share with me. I would also like to thank my colleagues, Josh McLellan and Hossein Nimrouzi, for their support, as well as Daniel Downey, Stanislav Tchernov, and Jianguo Zhou for their assistance with software troubleshooting. In addition, I would like to thank Dr. Jeremy Licht, formerly of AECL, for his keen insights regarding the conceptual design of the Canadian SCWR. Finally, I owe many thanks to the Department of Mechanical and Aerospace Engineering for their monetary support by way of the various research and teaching assistantships that they were so kind to grant me in my time here at Carleton University.

Further, I would like to thank Natural Resources Canada (NRCan) and the National Sciences and Engineering Research Council (NSERC) for their support of the Canadian Generation IV National Program. 


\section{Table of Contents}

Abstract

Acknowledgments iv

Table of Contents $\quad$ v

List of Tables viii

List of Figures ix

List of Acronyms xi

List of Symbols $\quad$ xiii

1 Introduction $\quad 1$

1.1 Background .......................... 1

1.1.1 Generation IV Canadian SCWR . . . . . . . . . . . . . . . 1

1.1.2 VrSuite Numerical Modelling Software . . . . . . . . . . . . 3

1.2 Literature Review . . . . . . . . . . . . . . . . . . . . . . 4

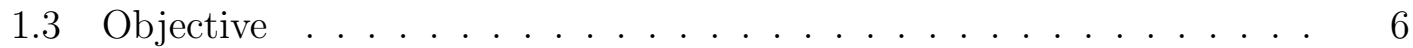

2 Methods $\quad 8$

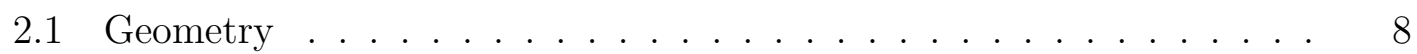

2.2 Governing Equations . . . . . . . . . . . . . . . . . . . . 11 
2.2 .1 Solid Domain . . . . . . . . . . . . . . . . . . . 11

2.2 .2 Fluid Domain . . . . . . . . . . . . . . . . . . 12

2.3 Discretization . . . . . . . . . . . . . . . . 16

2.4 Fluid/Material Properties _. . . . . . . . . . . . . . . . . . 17

2.4 .1 Thermal Analysis . . . . . . . . . . . . . . . . . 17

2.4 .2 Stress Analysis . . . . . . . . . . . . . . . . 20

2.5 Initial Conditions . . . . . . . . . . . . . . . . . . . 21

2.6 Boundary Conditions . . . . . . . . . . . . . . . . . . . . . 22

2.6.1 Thermal Analysis - Normal Operation . . . . . . . . . . 22

2.6.2 Thermal Analysis - LOCA . . . . . . . . . . . . . . 27

2.6.3 Stress Analysis . . . . . . . . . . . . . . . . . 33

2.7 Numerical Model . . . . . . . . . . . . . . . . . . . . . . . . . . 34

2.7.1 Solver Coupling . . . . . . . . . . . . . . . . . . . . 34

2.7.2 Simulation Parameters . . . . . . . . . . . . . . . 36

3 Results \& Discussion $\quad 38$

3.1 Maximum Cladding Surface Temperature . . . . . . . . . . . . . . . 39

3.2 Fuel Channel Efficiency . . . . . . . . . . . . . . . . . . . . . . . 44

$\begin{array}{llr}4 \text { Conclusions } & 48\end{array}$

4.1 Summary . . . . . . . . . . . . . . . . . . . . . . . . . 48

4.2 Future Work . . . . . . . . . . . . . . . . . . . 50

References $\quad 53$

Appendix A Time-Step Dependency Study 56

Appendix B VrSuite Verification - Thermal Solver 59

B.1 Numerical Solution . . . . . . . . . . . . . . . . . . . . . . . 59 
B.2 Analytical Solution . . . . . . . . . . . . . . . 60

B.3 Results . . . . . . . . . . . . . . . . . . 62

$\begin{array}{lll}\text { Appendix C VrSuite Verification - Stress Solver } & 63\end{array}$

C.1 Numerical Solution . . . . . . . . . . . . . . . . . . . . . . 63

C.2 Analytical Solution . . . . . . . . . . . . . . . . . . . 64

C.3 Results........................... . . 64

Appendix D VrSuite Verification - Radiation Solver $\quad 65$

D.1 Numerical Solution . . . . . . . . . . . . . . . . . . . 65

D.2 Analytical Solution . . . . . . . . . . . . . . . . . 66

D.3 Results . . . . . . . . . . . . . . . . . . . . . . . . 67

$\begin{array}{lll}\text { Appendix E Siemens NX 8.5/TMG Verification } & 70\end{array}$

E.1 Numerical Solution . . . . . . . . . . . . . . . . . . . . . 70

E.2 Analytical Solution . . . . . . . . . . . . . . . . . . . 71

E.3 Results . . . . . . . . . . . . . . . . . . . 71

$\begin{array}{lll}\text { Appendix F } & \text { Fuel Channel Design Optimization } & 73\end{array}$

Appendix G VrSuite Verification - Optimization Tool 75

G.1 Numerical Solution . . . . . . . . . . . . . . . . . . 75

G.2 Analytical Solution . . . . . . . . . . . . . . . . . . 77

G.3 Results . . . . . . . . . . . . . . . . . 78 


\section{List of Tables}

2.1 Component reference dimensions . . . . . . . . . . . . . . . . 9

2.2 Fuel pellet and cladding dimensions . . . . . . . . . . . . . . . . 9

2.3 Ratios of radiative to conductive thermal conductances across the water gaps ................................ 14

2.4 Order and range of polynomial curve fits . . . . . . . . . . . . 18

2.5 Coolant and moderator conditions during normal operation . . . . . . 22

2.6 Normal operation analysis duration and temperature/displacement changes at the final $\left(N^{t h}\right)$ time-step . . . . . . . . . . 36

3.1 Dimensions of the alternate fuel channel design . . . . . . . . . . 38

3.2 Water gap dimensions for the reference and alternate fuel channel designs 40

A.1 Reference design cladding temperatures at $\mathrm{t}=2 \mathrm{~s} \ldots \ldots . \ldots 57$

B.1 Thermal conductances and ambient temperatures prescribed at the inner surface of the inner liner . . . . . . . . . . . . . . . . 60

D.1 Steady-state thermal fluxes through the right volume element computed by numerical and analytical methods . . . . . . . . . . . . . . 68

F.1 Dimensional bounds for design variables that may be used for optimization of the fuel channel . . . . . . . . . . . . . . . . . . 73 


\section{List of Figures}

1.1 Fuel channel assembly and section view . . . . . . . . . . . . . 2

2.1 Top view of VrSuite thermal and stress geometries . . . . . . . . 8

2.2 Annotated detail view of thermal geometry . . . . . . . . . . . . . 9

2.3 Discretized reference geometry . . . . . . . . . . . . . . . . . . 16

2.4 Dimensionless thermofluid properties of water . . . . . . . . . . 17

2.5 Fuel channel component thermal conductivities versus temperature . 19

2.6 Thermal expansion coefficient and Young's modulus versus temperature 20

2.7 Heat transfer coefficient versus pressure tube surface temperature . . 26

2.8 Energy balance on a surface of finite area, $A_{k} \ldots \ldots . \ldots 27$

2.9 Top and detail views of the flow tube, fuel cladding, and inner liner modelled in TMG . . . . . . . . . . . . . . . . . . . . . . . 29

2.10 Boundary conditions used in the FEM stress analyses . . . . . . . . . 33

2.11 Data flow between the FEM thermal, radiation, and stress solvers . . 34

2.12 Demonstration of the maximum conductance concept . . . . . . . . 35

3.1 Inner fuel ring cladding temperatures versus time $(20,000 \mathrm{~s}) \quad \ldots \quad \ldots$

3.2 Inner fuel ring cladding temperatures versus time (first $60 \mathrm{~s}$ ) . . . . . 41

3.3 Scaled surface temperature versus time over the first $1.8 \mathrm{~s}$ following a

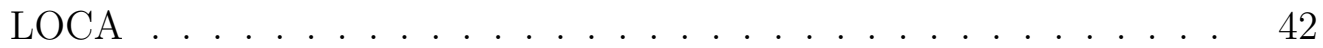

3.4 Time variation of the dimensionless LOCA thermal flux conducted by the inner liner $(20,000 \mathrm{~s}) \ldots \ldots \ldots \ldots$ 
3.5 Time variation of the dimensionless LOCA thermal flux conducted by the inner liner for the first $60 \mathrm{~s} \ldots \ldots \ldots 46$

A.1 Reference design cladding temperatures in the first $2 \mathrm{~s}$ following the

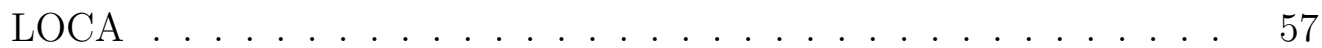

B.1 Thin fuel channel quadrant used to verify VrSuite's thermal solver . . 59

B.2 Schematic illustrating the fuel channel components and water gaps modelled as a series of thermal resistors . . . . . . . . . . . . . 61

B.3 Analytically and numerically derived radial temperature distributions 62

C.1 8-node volume element simulated in the VrSuite stress test case . . . 63

D.1 8-node volume elements simulated in the VrSuite radiation test case . 65

D.2 Numerically derived temperature distributions through the right volume element . . . . . . . . . . . . . . . . . . 67

E.1 Long rectangular enclosure used to verify the view factors derived from the Siemens NX 8.5/TMG FEM analyses . . . . . . . . . . . . . 70

G.1 Reference geometry and mesh used for verification of VrSuite's optimization tool .......................... 75

G.2 Objective function magnitude for the five initial tube designs . . . . . 78

G.3 Objective function magnitude for the final design space, consisting of seventeen outer tube radii $\ldots \ldots \ldots \ldots \ldots$ 


\title{
List of Acronyms
}

\author{
Acronym Definition \\ AECL Atomic Energy of Canada Limited \\ CATHENA Canadian Algorithm for THErmalhydraulic Network Analysis \\ CFD Computational Fluid Dynamics \\ $\mathrm{D}_{2} \mathrm{O} \quad$ Deuterium Oxide (heavy water) \\ DOE Design of Experiments \\ FEM Finite Element Method \\ GENHTP GENeralized Heat Transfer Package \\ GIF Generation IV International Forum \\ HEC High Efficiency Channel \\ HERC High Efficiency Re-entrant Channel \\ IAPWS International Association for the Properties of Water and Steam \\ IL Inner Liner \\ Ins Insulator
}




$\begin{array}{ll}\text { LOCA } & \text { Loss of Coolant Accident } \\ \text { MCST } & \text { Maximum Cladding Surface Temperature } \\ \text { NIST } & \text { National Institute of Standards and Technology } \\ \text { OL } & \text { Outer Liner } \\ \text { PMCS } & \text { Passive Moderator Cooling System } \\ \text { PT } & \text { Pressure Tube } \\ \text { SCWR } & \text { SuperCritical Water Reactor } \\ \text { YSZ } & \text { Yttria-Stabilized Zirconia }\end{array}$




\section{List of Symbols}

\section{Body}

Greek symbols and definitions (in alphabetical order):

\section{Greek Symbol Definition}

\begin{tabular}{ll}
\hline \hline$\sigma$ & Cauchy stress tensor $(\mathrm{Pa})$ \\
$\Omega_{\text {Cond }}$ & Conductance per unit area across a gap due to heat conduction \\
& $\left(\mathrm{W} / \mathrm{m}^{2} \cdot \mathrm{K}\right)$ \\
$\Omega_{\text {Conv }}$ & Conductance per unit area across a gap due to convection $\left(\mathrm{W} / \mathrm{m}^{2} \cdot \mathrm{K}\right)$ \\
$\Omega_{\text {Rad }}$ & Conductance per unit area across a gap due to thermal radiation \\
& $\left(\mathrm{W} / \mathrm{m}^{2} \cdot \mathrm{K}\right)$ \\
$\Omega_{\text {Asp }}$ & Conductance per unit area across a gap through the asperities of two \\
& surfaces in physical contact $\left(\mathrm{W} / \mathrm{m}^{2} \cdot \mathrm{K}\right)$ \\
$\rho_{m}$ & Density of the moderator $\left(\mathrm{kg} / \mathrm{m}^{3}\right)$ \\
$\rho_{s}$ & Density of the solid $\left(\mathrm{kg} / \mathrm{m}^{3}\right)$
\end{tabular}




$$
\mathrm{P}=100 \mathrm{kPa}(\mathrm{LOCA})\left(\mathrm{kg} / \mathrm{m}^{3}\right)
$$

$\rho^{*}$

$\nabla$

$\mu_{m}$

$\epsilon_{k}$

$\alpha$ and $\beta$

$\Delta t^{1}$

$\delta_{k j}$

$\Delta u_{M a x}^{N}$

$\Delta T_{M a x}^{N}$

$\nu$

$\gamma_{k}$

$\Delta t$

$\Delta t^{n}$

$\zeta$
Dimensionless density

Divergence operator

Dynamic viscosity of the moderator $(\mathrm{Pa} \cdot \mathrm{s})$

Emissivity of surface $k$

Experimentally derived functions of temperature and the surface

properties of two bodies in physical contact

Initial time-step size - exponential time-stepping ( $\mathrm{s})$

Kronecker-Delta

Maximum global displacement change between the penultimate and

final time-steps $(\mathrm{m})$

Maximum global temperature change between the penultimate and

final time-steps $(\mathrm{K})$

Poisson's ratio

Reflectivity of surface $k$

Size of time-step - constant time-stepping (s)

Size of time-step at $n^{\text {th }}$ time-step - exponential time-stepping (s)

Strain tensor $(\mathrm{m} / \mathrm{m})$ 
Temperature difference between the outer surface of the pressure tube and moderator $(\mathrm{K})$

$\tau$

Time constant for transient decay power (s)

$\Omega_{G}$

Total thermal conductance per unit area across a gap $\left(\mathrm{W} / \mathrm{m}^{2} \cdot \mathrm{K}\right)$

$\Omega_{\operatorname{Max}}$

User-specified maximum gap conductance per unit area $\left(\mathrm{W} / \mathrm{m}^{2} \cdot \mathrm{K}\right)$

$\eta$

Volumetric thermal expansion coefficient of the moderator $\left(\mathrm{K}^{-1}\right)$ 
General symbols and definitions (in alphabetical order):

\begin{tabular}{|c|c|}
\hline Symbol & Definition \\
\hline g & Acceleration of gravity $\left(\mathrm{m} / \mathrm{s}^{2}\right)$ \\
\hline$T_{\infty}$ & Ambient fluid temperature $\left(\mathrm{K}\right.$ or $\left.{ }^{\circ} \mathrm{C}\right)$ \\
\hline$T_{\infty, c}$ & Ambient coolant temperature $\left(\mathrm{K}\right.$ or $\left.{ }^{\circ} \mathrm{C}\right)$ \\
\hline$T_{\infty, m}$ & Ambient moderator temperature $\left(\mathrm{K}\right.$ or $\left.{ }^{\circ} \mathrm{C}\right)$ \\
\hline$A_{k}$ & Area of surface $\mathrm{k}\left(\mathrm{m}^{2}\right)$ \\
\hline $\mathrm{b}$ & Body force $(\mathrm{N})$ \\
\hline q & Conductive thermal flux in the solid domain $\left(\mathrm{W} / \mathrm{m}^{2}\right)$ \\
\hline$c_{p, m}$ & Constant pressure heat capacity of the moderator $(\mathrm{J} / \mathrm{kg} \cdot \mathrm{K})$ \\
\hline$c_{p, s}$ & Constant pressure heat capacity of the solid $(\mathrm{J} / \mathrm{kg} \cdot \mathrm{K})$ \\
\hline$c_{p, 0}$ & $\begin{array}{l}\text { Constant pressure heat capacity of water at } \mathrm{T}=300 \mathrm{~K} \text { and } \mathrm{P}=25 \mathrm{MPa} \\
\text { (normal operation) or } \mathrm{P}=100 \mathrm{kPa}(\mathrm{LOCA})(\mathrm{J} / \mathrm{kg} \cdot \mathrm{K})\end{array}$ \\
\hline$h_{C o n v}$ & Convective heat transfer coefficient $\left(\mathrm{W} / \mathrm{m}^{2} \cdot \mathrm{K}\right)$ \\
\hline$D_{F S}$ & Outer diameter of the fuel sheath (m) \\
\hline$c_{p}^{*}$ & Dimensionless constant pressure heat capacity \\
\hline$k^{*}$ & Dimensionless thermal conductivity \\
\hline$q^{*}$ & Dimensionless thermal flux rejected/lost by fuel bundle \\
\hline $\mathrm{u}$ & Displacement vector $(\mathrm{m})$ \\
\hline
\end{tabular}


D

L

$G r_{L}$

$h_{\text {Annulus }}$

$h_{\text {Fuel }}$

$h_{F T, I D}$

$h_{P T, O D}$

$D_{h}$

$P_{m, b}$

$P_{m, t}$

$D_{F T, I D}$

$r_{F S}$

$\mathrm{T}$ (superscript) Matrix transpose

$\left(\mathrm{W} / \mathrm{m}^{2} \cdot \mathrm{K}\right)$

flow tube $\left(\mathrm{W} / \mathrm{m}^{2} \cdot \mathrm{K}\right)$

inner liner $(\mathrm{m})$

Fourth-order tensor mapping strain tensor to Cauchy stress tensor (Pa)

Fuel channel length (m)

Grashof number evaluated at a characteristic length of L

Heat transfer coefficient between the coolant and flow tube (outer

surface)/inner liner (inner surface) $\left(\mathrm{W} / \mathrm{m}^{2} \cdot \mathrm{K}\right)$

Heat transfer coefficient between the coolant and fuel bundle cladding

Heat transfer coefficient between the coolant and inner surface of the

Heat transfer coefficient between the outer surface of the pressure tube and moderator $\left(\mathrm{W} / \mathrm{m}^{2} \cdot \mathrm{K}\right)$

Hydraulic diameter of the annular region between the flow tube and

Hydrostatic moderator pressure at the bottom of the fuel channel (Pa)

Hydrostatic moderator pressure at the top of the fuel channel $(\mathrm{Pa})$

Inner diameter of the flow tube $(\mathrm{m})$

Inner radius of the fuel sheath (m)

xvii 


\begin{tabular}{|c|c|}
\hline$T_{f}$ & Moderator film temperature $\left(\mathrm{K}\right.$ or $\left.{ }^{\circ} \mathrm{C}\right)$ \\
\hline$q_{k}$ & Net heat conducted away from surface $k\left(\mathrm{~W} / \mathrm{m}^{2}\right)$ \\
\hline$Q_{0}$ & Nominal reactor operating power - per fuel pin $(\mathrm{W})$ \\
\hline $\mathrm{n}$ & Normal vector \\
\hline $\operatorname{Pr}$ & Prandtl number \\
\hline$G_{k}$ & Radiant energy incident upon surface $k$ - irradiance $\left(\mathrm{W} / \mathrm{m}^{2}\right)$ \\
\hline$J_{k}$ & Radiant energy leaving surface $k$ - radiosity $\left(\mathrm{W} / \mathrm{m}^{2}\right)$ \\
\hline$R a_{L}$ & Rayleigh number evaluated at a characteristic length of $\mathrm{L}$ \\
\hline$R e_{D_{F S}}$ & Reynold's number evaluated at a characteristic length of $D_{F S}$ \\
\hline$R e_{D_{F T, I D}}$ & Reynold's number evaluated at a characteristic length of $D_{F T, I D}$ \\
\hline$R e_{D_{h}}$ & Reynold's number evaluated at a characteristic length of $D_{h}$ \\
\hline $\mathrm{a}$ & Scaling factor for exponential time-stepping \\
\hline$T_{s}^{*}$ & Scaled surface temperature \\
\hline S & Stefan-Boltzmann constant $\left(\mathrm{W} \cdot \mathrm{m}^{-2} \cdot \mathrm{K}^{-4}\right)$ \\
\hline$T_{s}$ & Surface temperature $\left(\mathrm{K}\right.$ or $\left.{ }^{\circ} \mathrm{C}\right)$ \\
\hline$T_{s, P T}$ & Surface temperature of the outside of the pressure tube $\left(\mathrm{K}\right.$ or $\left.{ }^{\circ} \mathrm{C}\right)$ \\
\hline$T^{+}$and $T^{-}$ & Surface temperatures on either side of a gap $\left(\mathrm{K}\right.$ or $\left.{ }^{\circ} \mathrm{C}\right)$ \\
\hline $\mathrm{T}$ & Temperature $\left(\mathrm{K}\right.$ or $\left.{ }^{\circ} \mathrm{C}\right)$ \\
\hline$T_{k}$ & Temperature of surface $\mathrm{k}\left(\mathrm{K}\right.$ or $\left.{ }^{\circ} \mathrm{C}\right)$ \\
\hline
\end{tabular}


$T_{I L, S-S}$

$k_{G}$

$k_{m}$

$k_{s}$

$k_{c}$

$k_{0}$

$q_{\text {Sheath }}$

$q_{C o n v}$

$q_{L O C A}$

$q_{\text {Normal }, S-S}$

t

$q_{G}$

$F_{k-j}$

Q

W
Temperature at the inner surface of the inner liner during normal operation at steady-state $\left(\mathrm{K}\right.$ or $\left.{ }^{\circ} \mathrm{C}\right)$

Thermal conductivity of the gap medium $(\mathrm{W} / \mathrm{m} \cdot \mathrm{K})$

Thermal conductivity of the moderator $(\mathrm{W} / \mathrm{m} \cdot \mathrm{K})$

Thermal conductivity of the solid $(\mathrm{W} / \mathrm{m} \cdot \mathrm{K})$

Thermal conductivity of the supercritical coolant water $(\mathrm{W} / \mathrm{m} \cdot \mathrm{K})$

Thermal conductivity of water at $\mathrm{T}=300 \mathrm{~K}$ and $\mathrm{P}=25 \mathrm{MPa}$ (normal

operation) or $\mathrm{P}=100 \mathrm{kPa}(\mathrm{LOCA})(\mathrm{W} / \mathrm{m} \cdot \mathrm{K})$

Thermal flux upon the fuel sheath due to nuclear fission (normal

operation) or decay heat (LOCA) $\left(\mathrm{W} / \mathrm{m}^{2}\right)$

Thermal flux via convective heat transfer $\left(\mathrm{W} / \mathrm{m}^{2}\right)$

Thermal flux rejected by the fuel bundle during a LOCA $\left(\mathrm{W} / \mathrm{m}^{2}\right)$

Thermal flux lost by the fuel bundle during normal operation at

steady-state $\left(\mathrm{W} / \mathrm{m}^{2}\right)$

Time (s)

Total thermal flux across a gap $\left(\mathrm{W} / \mathrm{m}^{2}\right)$

View factor from surface $k$ to surface $j$

Volumetric heat source or sink $\left(\mathrm{W} / \mathrm{m}^{3}\right)$

Width of a water gap (m) 


\section{Appendices}

Greek symbols and definitions (in alphabetical order):

\section{Greek Symbol Definition}

$\Delta L_{A} \quad$ Analytically predicted change in length of the element (m)

$\sigma_{a} \quad$ Axial stress $(\mathrm{Pa})$

$\Delta L \quad$ Change in length of the element after heating from $\mathrm{T}_{o}$ to $\mathrm{T}(\mathrm{m})$

$\sigma_{\theta} \quad$ Circumferential stress $(\mathrm{Pa})$

$\lambda \quad$ Linear coefficient of thermal expansion $\left(\mathrm{K}^{-1}\right)$

$\Delta L_{N} \quad$ Numerically predicted change in length of the element $(\mathrm{m})$

$\kappa \quad$ Objective function $\left(\mathrm{Pa}^{2}\right)$

$\sigma_{11}, \sigma_{22}$, and $\sigma_{33}$ Principal stresses $(\mathrm{Pa})$

$\sigma_{r} \quad$ Radial stress $(\mathrm{Pa})$

$\delta \quad$ Scaling factor

$\theta \quad$ Strain $(\mathrm{m} / \mathrm{m})$

$\Delta T_{i} \quad$ Temperature drop across fuel channel component $i(\mathrm{~K})$

$\Delta T_{R} \quad$ Temperature drop across the right-most element (K)

$\sigma_{V M} \quad$ Von Mises (effective) stress $(\mathrm{Pa})$ 
General symbols and definitions (in alphabetical order):

\section{Symbol Definition}

\begin{tabular}{|c|c|}
\hline$T_{\infty, c}$ & Ambient coolant temperature $\left(\mathrm{K}\right.$ or $\left.{ }^{\circ} \mathrm{C}\right)$ \\
\hline$q_{\text {Right,A}}$ & $\begin{array}{l}\text { Analytically predicted thermal flux conducted through the right-most element } \\
\left(\mathrm{W} / \mathrm{m}^{2}\right)\end{array}$ \\
\hline$r_{o, A}^{*}$ & Analytically predicted optimum outer pipe radius $(\mathrm{mm})$ \\
\hline$k_{I L}$ & Average thermal conductivity of the inner liner $(\mathrm{W} / \mathrm{m} \cdot \mathrm{K})$ \\
\hline$T_{o}$ & Initial temperature $\left(\mathrm{K}\right.$ or $\left.{ }^{\circ} \mathrm{C}\right)$ \\
\hline$r_{i}$ & Inner pipe radius $(\mathrm{m})$ \\
\hline$r_{i, I L}$ & Inner radius of the inner liner $(\mathrm{m})$ \\
\hline $\mathrm{p}$ & Internal pipe pressure $(\mathrm{Pa})$ \\
\hline $\mathrm{L}(\mathrm{T})$ & Length of the element at temperature $\mathrm{T}(\mathrm{m})$ \\
\hline $\mathrm{L}\left(\mathrm{T}_{o}\right)$ & Length of the element at temperature $\mathrm{T}_{o}(\mathrm{~m})$ \\
\hline $\mathrm{L}_{R}$ & Length of the right-most element (m) \\
\hline $\mathrm{L}$ & Length of the rectangular enclosure $(\mathrm{m})$ \\
\hline$r_{o, N}^{*}$ & Numerically predicted optimum outer pipe radius (mm) \\
\hline$r_{o}$ & Outer pipe radius $(\mathrm{m})$ \\
\hline$r_{o}^{*}$ & Optimum outer pipe radius $(\mathrm{m})$ \\
\hline
\end{tabular}


$r_{o, I L} \quad$ Outer radius of the inner liner $(\mathrm{m})$

$T_{l} \quad$ Steady-state inner liner temperature $\left(\mathrm{K}\right.$ or $\left.{ }^{\circ} \mathrm{C}\right)$

$q_{\text {Left }} \quad$ Heat conducted through the left-most element $\left(\mathrm{W} / \mathrm{m}^{2}\right)$

$q_{\text {Ref }} \quad$ Heat radiated by the left-most element and reflected by the right-most element $\left(\mathrm{W} / \mathrm{m}^{2}\right)$

$q_{\text {Surr }} \quad$ Heat radiated by the left-most element and absorbed by the surroundings $\left(\mathrm{W} / \mathrm{m}^{2}\right)$

$q_{\text {Right }, N} \quad$ Numerically predicted thermal flux conducted through the right-most element $\left(\mathrm{W} / \mathrm{m}^{2}\right.$

$R_{h, c} \quad$ Thermal resistance across the coolant-side thermal boundary layer (K/W)

$R_{I L} \quad$ Thermal resistance across the inner liner $(\mathrm{K} / \mathrm{W})$

$R_{i} \quad$ Thermal resistance across fuel channel component $i(\mathrm{~K} / \mathrm{W})$

$Q_{\text {Tot }} \quad$ Total rate of heat transfer between the coolant and moderator (W)

$\mathrm{S}_{y} \quad$ Yield stress $(\mathrm{Pa})$ 


\section{Chapter 1}

\section{Introduction}

\subsection{Background}

\subsubsection{Generation IV Canadian SCWR}

As a prominent member of the GIF (Generation IV International Forum), Canada has been actively involved in the research and conceptual design of Generation IV fission reactors. One of these novel reactor concepts is the SCWR (SuperCritical Water Reactor), which makes use of supercritical water cooling of the Uranium/Thorium fuel [1].

In its current iteration, the Canadian SCWR design features 336 fuel channels (2,540 $\mathrm{MW}_{t h}$ total power) immersed in a heavy water moderator [1][2]. Each of these $5 \mathrm{~m}$ long fuel channels consist of 64 fuel pins clad in stainless steel, liner tubes (also stainless steel), a YSZ (Yttria-Stabilized Zirconia) ceramic insulator, and a zircaloy pressure tube to contain the assembly. In the HEC (High Efficiency Channel) configuration presented in this thesis, the supercritical water coolant flows downward through a central flow tube, back upwards through the fuel bundle, and exits the fuel channel through an outlet plenum. Figure 1.1 illustrates the operation of a typical fuel channel: 

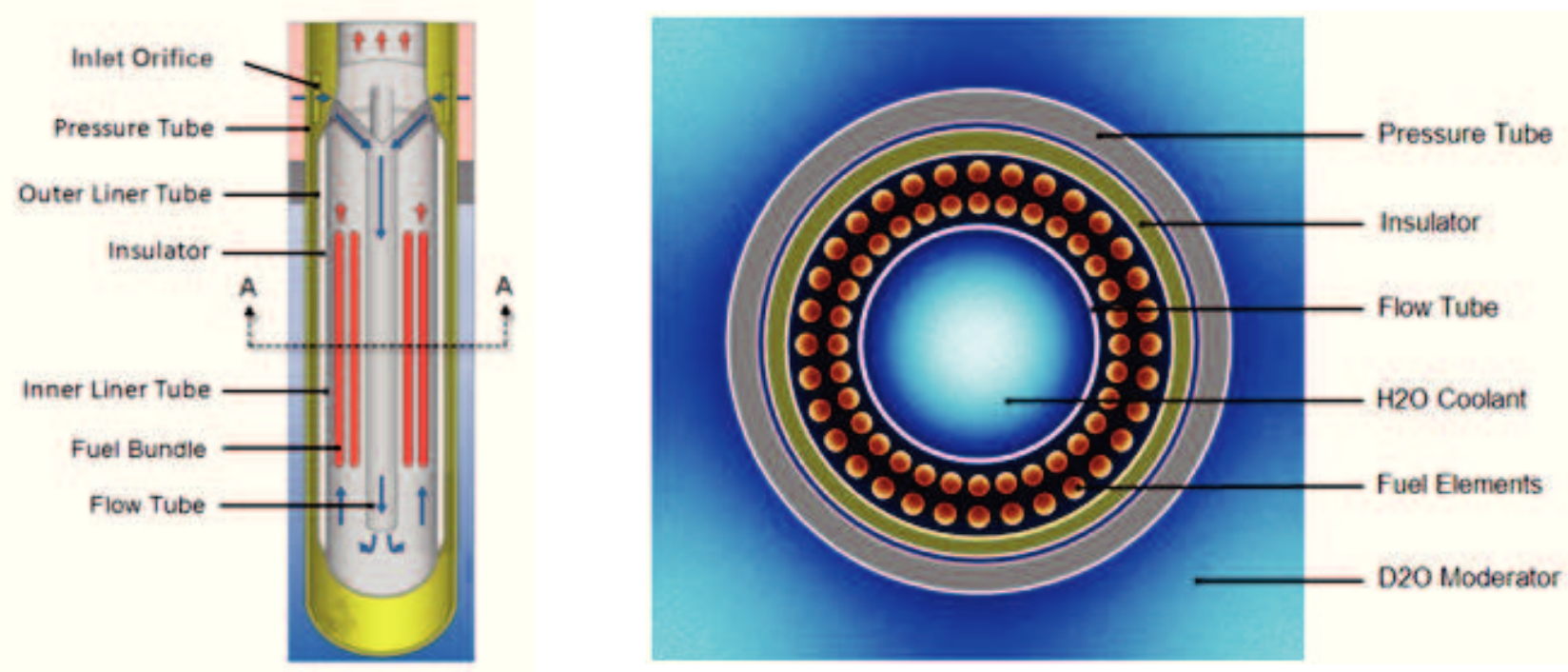

Figure 1.1: Fuel channel assembly (left, NTS) and section view A-A (right) ${ }^{1}$.

With the configuration displayed in Figure 1.1, coolant temperatures of $350{ }^{\circ} \mathrm{C}$ and $625{ }^{\circ} \mathrm{C}$ are achieved at the bottom and top of the fuel channel, respectively, with a constant operating pressure of $25 \mathrm{MPa}$. On the moderator-side, the heavy-water is maintained at a pressure of $300 \mathrm{kPa}$ and temperature of $80^{\circ} \mathrm{C}$ via active moderator cooling [3]. The reader may refer to Chapter $\mathbf{2}$ Methods for further quantitative data concerning dimensions, operating conditions, etc.

During a LOCA (Loss of Coolant Accident), the supercritical water coolant inventory is rapidly depleted and the control rods are subsequently inserted into the core. In the time that transpires between the LOCA and full control rod deployment, nuclear fission continues to generate heat within the fuel pellets. Full insertion is followed by radioactive decay of the fission products which generates heat at approximately $7 \%$ of the $2,540 \mathrm{MW}_{t h}$ nominal power. These combined effects will cause a rise in temperature in the fuel and its cladding which, if left unchecked, may cause melting of the fuel assembly.

\footnotetext{
${ }^{1}$ Both images courtesy of [2].
} 
To mitigate damage in the event of such an accident, the GIF participant nations have resolved to research and implement new safety provisions in next generation reactors. Foremost among these is a passive safety feature, named the "no-core-melt" concept by AECL (Atomic Energy of Canada Limited). In no-core-melt, the excess heat resulting from the LOCA is radiated from the high-temperature fuel cladding to the inner liner, conducted through the other fuel channel components, and is ultimately deposited into the moderator which may serve as an emergency heat sink during accidents. With a proper selection of fuel channel assembly dimensions, it may be possible to reject sufficient heat to the moderator such that the fuel cladding is limited to submelting $\left(1,450{ }^{\circ} \mathrm{C}\right.$ for stainless steel $)$ temperatures during a LOCA.

\subsubsection{VrSuite Numerical Modelling Software}

VrSuite is an FEM (Finite Element Method) multiphysics software package developed

by Goldak Technologies Inc ${ }^{\circledR}$. The software is designed to efficiently solve coupled, transient problems in three spatial dimensions. All coupled thermal/stress simulations described in this thesis utilized VrSuite, with the exception of the numerical computation of the fuel bundle view factors (see Section 2.6.2 Thermal Analysis - LOCA for details).

The reader may refer to the appendices for information regarding verification of the VrSuite software. 


\subsection{Literature Review}

By examining research performed by others, yet similar in content to that presented in this thesis, it was possible to identify potential expansions of scope as well as novel areas of study.

Wu, et al. [4] simulated two-dimensional radiation and conduction heat transfer in an HEC using the SCTRAN code. Specifically, they studied the inner and outer ring fuel sheath temperatures in a 64-pin fuel bundle during a LOCA. They observed an equilibrium between decay heat and thermal radiation from the fuel bundle when the fuel channel power decreased to $2.5 \%$ of the nominal power, with MCST's (Maximum Cladding Surface Temperature) of $1,296{ }^{\circ} \mathrm{C}$ and $1,253{ }^{\circ} \mathrm{C}$ in the inner and outer rings, respectively. These results supported a favourable argument for the no-coremelt concept, assuming stainless steel for the fuel sheathing material with melting temperatures ranging from $1,300{ }^{\circ} \mathrm{C}$ to $1,500{ }^{\circ} \mathrm{C}$.

Sensitivity analyses were also conducted in [4], wherein selected parameters were varied independently and the effects upon the LOCA fuel sheath temperatures were studied. The authors reported that the MCST differed by $180{ }^{\circ} \mathrm{C}$ when the coolantside natural convection heat transfer coefficient was permitted to range from 1 $\mathrm{W} / \mathrm{m}^{2} \cdot \mathrm{K}$ to $38 \mathrm{~W} / \mathrm{m}^{2} \cdot \mathrm{K}$, with higher temperatures occurring for smaller heat transfer coefficients. In contrast, changes in the outlet plenum volume and moderator side heat transfer coefficient instigated relatively small deviations in fuel sheath temperature (approximately $13^{\circ} \mathrm{C}$ ).

Licht [3] performed CFD (Computational Fluid Dynamics) analyses to estimate the heat transferred between a heavy water moderator and pressure tube in both HEC and HERC (High Efficiency Re-entrant Channel) configurations. In particular, the thickness and thermal conductivity of the insulator were varied and the required moderator subcooling and mass flow rate were estimated to prevent nucleate boiling 
at the moderator/pressure tube interface.

A preliminary assessment of no-core-melt in the Generation IV Canadian SCWR was performed by Licht and $\mathrm{Xu}$ [5]. Using the CATHENA (Canadian Algorithm for THErmalhydraulic Network Analysis) numerical modelling software, they performed transient simulations of heat exchange between a 78-pin fuel bundle and heavy water moderator in LOCA conditions. They observed that for decay heat profiles $\leq 3 \%$ of nominal channel power a state of no-core-melt was achieved, whereas beyond this threshold fuel bundle melting ensued.

Shan, Jiang, and Leung [6] studied the effects of varying the LOCA decay heat (as a percent of the nominal channel power), moderator/pressure tube heat transfer coefficient, and insulator thermal conductivity upon the fuel cladding temperature in an HEC configuration. Using the CATHENA thermal-hydraulic code with only radiation heat exchange between the 54-pin fuel bundle and inner liner tube, they observed that the decay heat had the most substantial impact upon the cladding temperature, with quantities of $\leq 2 \%$ (the film coefficient and insulator conductivity remaining constant at their reference values) yielding sub-melting temperatures (i.e, $\mathrm{T} \leq 1,350^{\circ} \mathrm{C}$ ) for a stainless steel cladding.

Vasic and Khartabil [7] examined the effects of thermophysical insulator properties upon the fuel center-line temperatures during a LOCA for a 43-pin, supercritical water cooled fuel bundle. They used CATHENA and GENHTP (GENeralized Heat Transfer Package) software packages to model heat transfer between the fuel assembly and heavy water moderator via conduction and radiation in an HEC. They observed that for insulator thermal conductivities of $k>2 \mathrm{~W} / \mathrm{m} \cdot \mathrm{K}$, the fuel center-line temperatures fell below their threshold of $2,000{ }^{\circ} \mathrm{C}$. However, for $k<2 \mathrm{~W} / \mathrm{m} \cdot \mathrm{K}$ the maximum fuel temperature exceeded this threshold and insufficient heat was rejected to the moderator during a LOCA, meaning that overheating occurred in the insulator and pressure tube. 


\subsection{Objective}

The analyses described in this thesis were intended to expand upon the research summarized in Section 1.2 Literature Review. This was done by exploring facets of the no-core-melt concept that had not been investigated in the literature.

For the sake of simplicity, [4]-[7] modelled the water gaps between components as a series of perfect thermal contacts. This assumption implied zero temperature drops across these gaps, which are in turn analogous with infinite thermal conductances. In the study presented here, the thermal and stress solvers were coupled together within the VrSuite FEM software. This was done to capture the complex relationship between the heat conducted across the water gaps and the relative deformations of the fuel channel components when subjected to thermal and mechanical loads.

Iterations between thermalhydraulic design and nuclear physics have occurred in the conceptual design phase of the Canadian SCWR. For example, previous work had studied fuel bundle designs consisting of 43, 54, 78, and 64 (current design) pins; a distinction that would likely have a significant effect upon heat transfer through the fuel channel. For this reason, it was important to assess the feasibility of the no-core-melt concept using an up-to-date fuel channel configuration.

Documents [4]-[7] simulated heat exchange between the fuel bundle and moderator while permitting selected parameters to vary. These sensitivity studies granted the authors insight into the many different forces driving heat exchange in the Canadian SCWR. The present analysis intends to follow suit by studying heat transfer in two distinct fuel channel designs provided by AECL. Through VrSuite simulations of these designs, it was possible to identify the configuration which attained a state of no-core-melt more efficiently. 
The techniques detailed previously are intended to facilitate a new methodology for studying heat flow through a fuel channel in the Canadian SCWR. Future work may utilize this methodology for assessment of other fuel channel designs, with the ultimate goal being design optimization. 


\section{Chapter 2}

\section{Methods}

\subsection{Geometry}

A reference fuel channel design was simulated in VrSuite to ascertain a benchmark for the heat transferred from the fuel bundle to moderator in normal and LOCA operation. Screenshots of the geometry analyzed in VrSuite are shown in Figure 2.1 with detail A illustrated in Figure 2.2. The dimensions are summarized in Tables 2.1 and 2.2:
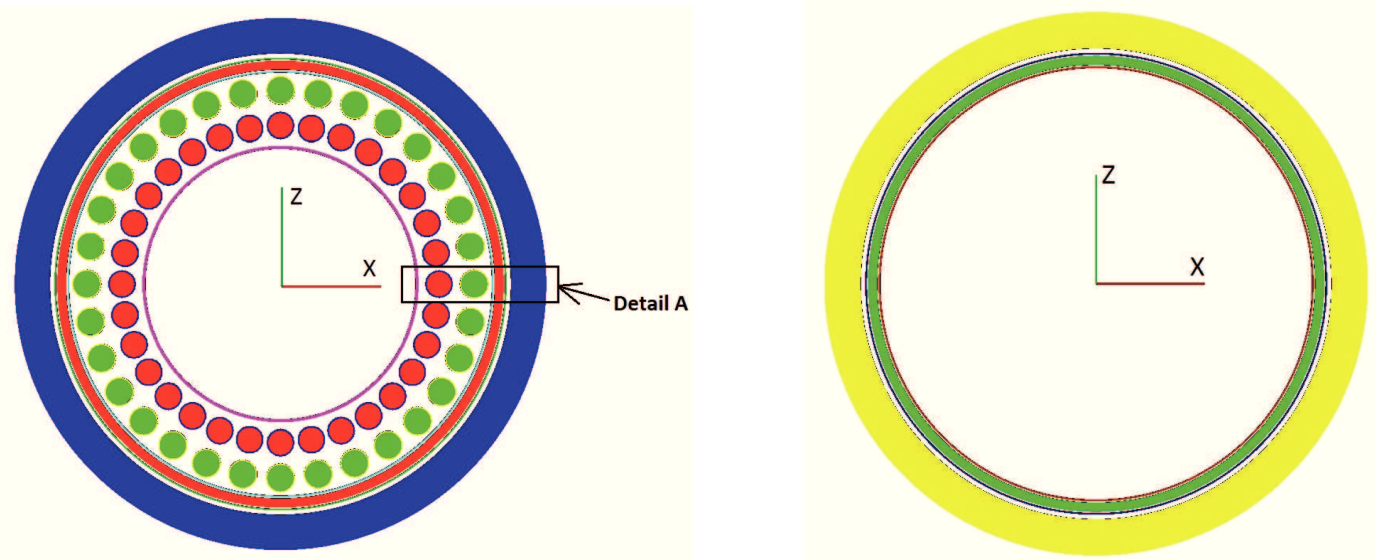

Figure 2.1: Top view of the geometries simulated in the VrSuite thermal (left) and stress (right) simulations. The location of detail view A is also shown. 


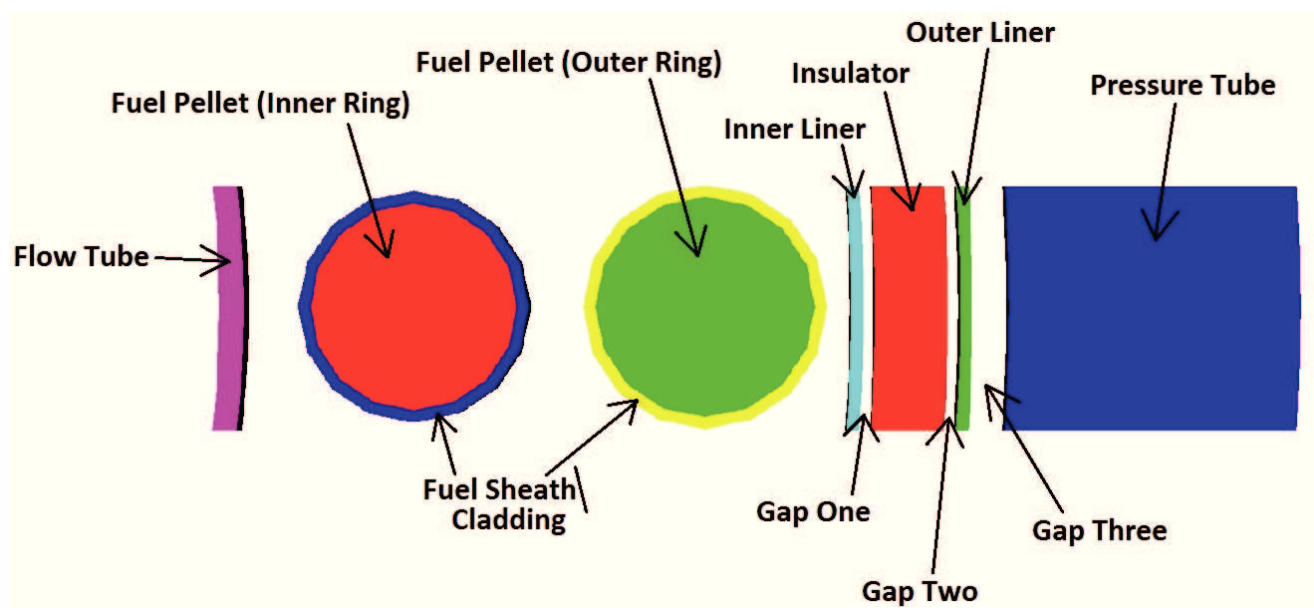

Figure 2.2: Detail view A with the fuel channel components labelled.

Table 2.1: Reference dimensions for the fuel channel components.

\begin{tabular}{|c|c|c|}
\hline Component & Inner Radius $(\mathrm{mm})$ & Outer Radius $(\mathrm{mm})$ \\
\hline Flow Tube & 46.0 & 47.0 \\
\hline Inner Liner & 72.0 & 72.5 \\
\hline Gap One & 72.5 & 73.0 \\
\hline Insulator & 73.0 & 76.0 \\
\hline Gap Two & 76.0 & 76.5 \\
\hline Outer Liner & 76.5 & 77.0 \\
\hline Gap Three & 77.0 & 78.5 \\
\hline Pressure Tube & 78.5 & 90.5 \\
\hline
\end{tabular}

Table 2.2: Dimensions for the inner and outer ring fuel pellets and cladding.

\begin{tabular}{|c|c|c|}
\cline { 2 - 3 } \multicolumn{1}{c|}{} & Inner Fuel Ring & Outer Fuel Ring \\
\hline Pitch Radius $(\mathrm{mm})$ & 54.0 & 66.0 \\
\hline Fuel Pellet Radius $(\mathrm{mm})$ & 4.25 & 4.5 \\
\hline Cladding Thickness $(\mathrm{mm})$ & 0.5 & 0.5 \\
\hline
\end{tabular}


Worthy of note is that the fuel bundle and flow tube were not modelled in the stress analyses because the displacements of these components were not coupled to those of the liner tubes, insulator, and pressure tube. Therefore, these particular deformations were deemed immaterial to heat exchange in the fuel channel and were not of interest.

When one considers the temperature difference between the coolant and moderator, it is evident that the radial temperature gradient will be a significant driver of heat transfer through the fuel channel. Specifically, bulk coolant and moderator temperatures of $625{ }^{\circ} \mathrm{C}$ and $80{ }^{\circ} \mathrm{C}$, respectively, yield a radial temperature gradient of $30{ }^{\circ} \mathrm{C} / \mathrm{mm}$ between the inner liner and outer surface of the pressure tube - a length of $18.5 \mathrm{~mm}$.

By comparison, the axial temperature gradient may be considered negligibly small. Specifically, bulk coolant temperatures of $350{ }^{\circ} \mathrm{C}$ and $625^{\circ} \mathrm{C}$ at the bottom and top of the fuel channel, respectively, imply an axial temperature gradient of $0.06{ }^{\circ} \mathrm{C} / \mathrm{mm}$ along the $5 \mathrm{~m}$ fuel channel length. Consequently, a single cross-section ${ }^{2}$ of $0.5 \mathrm{~mm}$ axial thickness was simulated at the top of the fuel channel in lieu of the full 5 $m$ length. This simplification was made to circumvent the computational expense associated with modelling the full length of the assembly. The cross-section was selected at the top of the fuel channel in the interest of conservative design, as the highest coolant temperatures are predicted in this vicinity. However, cross-sections could be selected at any height if desired.

\footnotetext{
${ }^{2}$ Although the axial temperature gradient may be considered negligible in this analysis, the VrSuite software by default solves all governing equations in three spatial dimensions.
} 


\subsection{Governing Equations}

\subsubsection{Solid Domain}

The conservation of energy equation governs the time evolution of the solid domain temperature distribution [8][9], as shown:

$$
\nabla \cdot q+Q=\rho_{s} c_{p, s} \frac{D T}{D t}
$$

Where, as per Fourier's law:

$$
q=-k_{s} \nabla T
$$

Equation (2.1) was discretized in both space and time, with VrSuite being used to solve for the thermal fluxes, and thus the temperatures, via FEM techniques.

The volumetric heat source term, $Q$, simulated thermal energy generated either by nuclear fission (normal operation) or decay heat (LOCA) in the fuel pellets. As the VrSuite software does not support user-defined time-dependent volumetric heat sources in the fuel pellets, $Q$ was simulated as a thermal flux boundary condition on the inner surface of the fuel cladding. More information may be found in Section 2.6

\section{Boundary Conditions.}

Strain due to thermal and mechanical loads is governed by the conservation of momentum equation [9], as shown:

$$
\begin{gathered}
\nabla \cdot \sigma+b=0 \\
\sigma=D \zeta \\
\zeta=\left[\nabla u+(\nabla u)^{T}+(\nabla u)^{T} \nabla u\right] / 2
\end{gathered}
$$

As with the conservation of energy equation, (2.3)-(2.5) were discretized and solved using the VrSuite FEM software. It should be noted that all deformations resulting 
from mechanical and thermal loads were assumed to be small and therefore elastic in order to simplify the analysis. This assumption was confirmed by monitoring the maximum stress in the pressure tube over the course of the normal operation simulations. Results from the LOCA simulations were not considered given the lower coolant pressure and pressure tube stresses. A maximum circumferential stress of 204 MPa was observed at steady-state, which fell below the Zircaloy-2 yield strength of $760 \mathrm{MPa}$ (for an average steady-state pressure tube temperature of about $125^{\circ} \mathrm{C}$ ) [10]. Stresses in the liners and insulator were not investigated since they were generally an order of magnitude less than those found in the pressure tube.

Furthermore, inertial forces (i.e, acoustic waves) were assumed negligible, implying that the stress analyses were quasi-static.

\subsubsection{Fluid Domain}

Heat transfer across the three water gaps is governed by the following four mechanisms [11]:

- Conduction through the water/steam present in the gaps.

- Natural and/or forced convection of the water/steam.

- Thermal radiation between the bounding surfaces.

- Through the enmeshing asperities when/if physical contact is made between the two surfaces bounding the gap.

At microscopic length scales, rough surfaces are characterized by rugged protrusions or "asperities". When two surfaces make physical contact, heat is transferred both through these contacting asperities and the interstitial gas layer [12], as highlighted by the fourth bullet. 
The magnitudes of the four heat exchange mechanisms illustrated previously may be represented by a thermal conductance per unit area ${ }^{3}$. In turn, each of these conductances may be added together to yield the total conductance across the gap, as follows:

$$
\Omega_{G}=\Omega_{C o n d}+\Omega_{C o n v}+\Omega_{R a d}+\Omega_{A s p}
$$

Where the resulting thermal flux across the gap may then be expressed as shown:

$$
q_{G}=\Omega_{G}\left(T^{+}-T^{-}\right)
$$

As VrSuite currently does not provide user-support for simulating the latter three conductances in Equation (2.6), only $\Omega_{\text {Cond }}$ was considered in the analyses described in this thesis. This conductance due to conduction across the gap may be expressed as follows:

$$
\Omega_{\text {Cond }}=\frac{k_{G}}{W}
$$

However, it is beneficial to consider the magnitudes of the latter three conductances in Equation (2.6) in order to estimate the amount of error resulting from their exclusion. Regarding the convection term, it was assumed that this heat transfer mechanism would be negligible in comparison with conduction given the small widths of the gaps.

\footnotetext{
${ }^{3}$ All instances of thermal conductance $\Omega$ in this thesis utilize units of $\mathrm{W} / \mathrm{m}^{2} \cdot \mathrm{K}$, meaning that the correct terminology would be thermal conductance per unit area. For brevity, all future instances of "thermal conductance" imply "thermal conductance per unit area".
} 
The thermal conductance via radiation across the gaps may be computed via the Stefan-Boltzmann law with the view factor between surfaces assigned a value of unity for simplicity:

$$
\Omega_{R a d}=S\left[\left(T^{+}\right)^{2}-\left(T^{-}\right)^{2}\right]\left(T^{+}-T^{-}\right)
$$

It is most convenient to compare the conductive and radiative conductances using the steady-state temperatures/water gap widths in normal operation. This state is also applied at the beginning (i.e, $\mathrm{t}=0 \mathrm{~s}$ ) of the LOCA with only the gap media changing from liquid/supercritical water to superheated steam (or $\mathrm{P}=25 \mathrm{MPa}$ in normal operation to $\mathrm{P}=100 \mathrm{kPa}$ in LOCA). Calculating $\Omega_{\text {Cond }}$ as per Equation (2.8), the ensuing ratios may be found in Table 2.3:

Table 2.3: Ratios of radiative to conductive thermal conductances across the water gaps at steady-state (normal operation) and initial conditions (LOCA).

\begin{tabular}{|c|c|c|}
\cline { 2 - 3 } \multicolumn{1}{c|}{} & \multicolumn{2}{c|}{$\Omega_{\text {Rad }} / \Omega_{\text {Cond }}$} \\
\cline { 2 - 3 } \multicolumn{1}{c|}{} & Normal Operation & LOCA \\
\hline Gap One & 0.059 & 0.093 \\
\hline Gap Two & 0.028 & 0.44 \\
\hline Gap Three & 0.045 & 0.96 \\
\hline
\end{tabular}

Table 2.3 would suggest that conduction dominates heat transfer across the water gaps in normal operation. This is a result of the high thermal conductivity of the liquid/supercritical water in the gaps at $\mathrm{P}=25 \mathrm{MPa}$. Conversely, the low conductivity steam present in the LOCA impedes conduction, in turn meaning that radiation conductance constitutes a non-negligible driver of heat transfer across the gaps. Thus, it appears that modelling conductance across the water gaps via conduction alone is insufficient in gaps two and three at LOCA, whereas the exclusion of $\Omega_{\text {Rad }}$ in normal operation will result in only small discrepancies. 
The current technique for computing the heat exchange between two surfaces in physical contact has been expanded upon in Section 2.7.1 Solver Coupling. The requirements for a more rigorous model of the conductance through asperities will be discussed in Section 4.2 Future Work.

During normal operation, heat is convected away from the fuel cladding by upward flowing supercritical water coolant. The ensuing heat flux is dictated by Newton's law of cooling:

$$
q_{C o n v}=h_{C o n v}\left(T_{s}-T_{\infty}\right)
$$

The reader may refer to Section 2.6.1 Thermal Analysis - Normal Operation for the correlations utilized to estimate the value of $h_{C o n v}$.

By contrast, during a LOCA the primary mechanism of heat rejection from the fuel cladding is thermal radiation. The laws governing this phenomenon have been expounded in Section 2.6.2 Thermal Analysis - LOCA. 


\subsection{Discretization}

Each of the fuel channel components detailed in Table 2.1 were discretized with 256 equally sized 8-node volume elements in the circumferential dimension. The crosssections of these elements were maintained uniform with dimensions of $0.5 \mathrm{~mm} \times 0.5$ $\mathrm{mm}$. The fuel pellets were meshed in a similar manner, albeit with 16 divisions in the circumferential dimension for each pin. A screenshot of the discretized reference fuel channel assembly may be found in Figure 2.3:
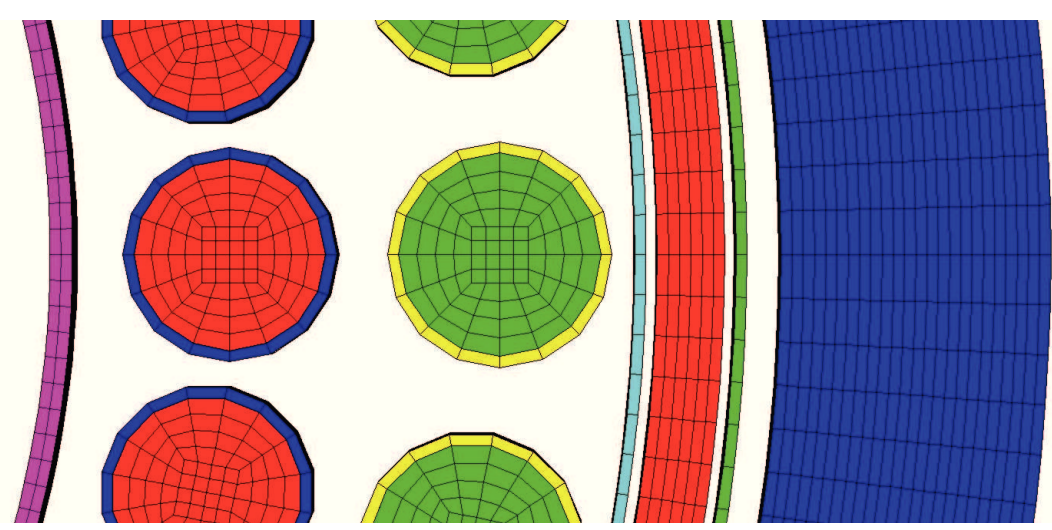

Figure 2.3: Screenshot from VrSuite depicting the discretized reference geometry.

It should be noted that the number of circumferential divisions and cross-section dimensions were initially selected arbitrarily. To test the accuracy of the mesh illustrated in Figure 2.3, a simple test problem was solved as detailed in Appendix B: VrSuite Verification - Thermal Solver. This simplified analog was utilized to avoid the complex geometry and associated difficulty of finding an analytical solution. The test mesh yielded temperature distributions that agreed well with analytical results. Therefore, a mesh sensitivity study was deemed to be unnecessary.

In addition, the water gaps and interfaces between the fuel cladding and Uranium/Thorium fuel pellets were meshed with contact elements. This was done in 
order to circumvent the numerical ill-conditioning problems typical of volume elements as their lengths approach zero.

\subsection{Fluid/Material Properties}

\subsubsection{Thermal Analysis}

Given the large radial temperature gradients expected in both normal and accident operating conditions, temperature-dependent coolant thermal properties were used in the thermal simulations. The relevant water/steam data were compiled from NIST (National Institute of Standards and Technology) [13] and IAPWS (International Association for the Properties of Water and Steam) [14] for pressures of $25 \mathrm{MPa}$ (normal operation) and $100 \mathrm{kPa}$ (LOCA). The dimensionless density, constant pressure specific heat capacity, and thermal conductivity as functions of temperature have been reproduced in Figure 2.4 from [15]:
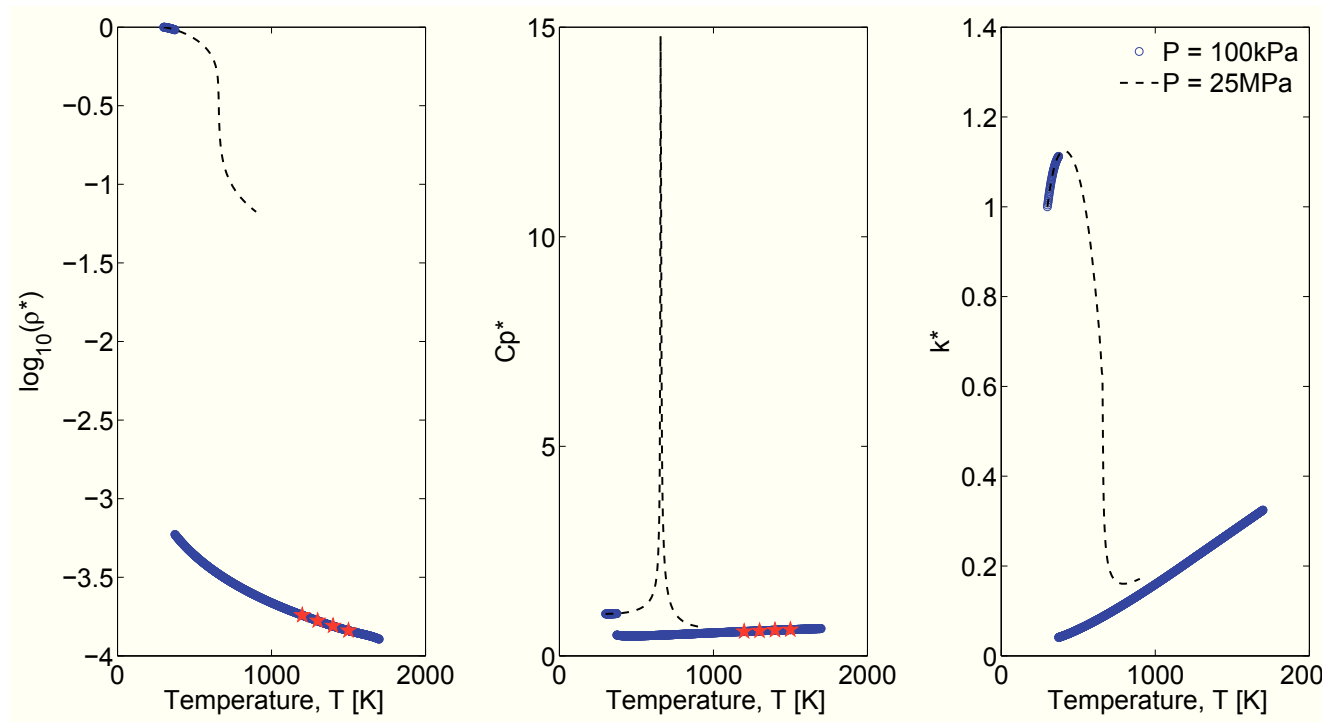

Figure 2.4: Dimensionless density (left), constant pressure specific heat capacity (center), and thermal conductivity (right). The red stars symbolize data taken from IAPWS-97 for $T>1,275 \mathrm{~K}$, for which fluid properties from NIST were unavailable. 
Where the dimensionless properties seen in Figure 2.4 are defined as follows:

$$
\begin{gathered}
\rho^{*}(T)=\rho(T) / \rho_{0} \\
c_{p}^{*}(T)=c_{p}(T) / c_{p, 0} \\
k^{*}(T)=k(T) / k_{0}
\end{gathered}
$$

For $300 \mathrm{~K} \leq \mathrm{T} \leq 1,275 \mathrm{~K}$, all fluid property data were acquired from NIST. However, beyond the upper temperature bound data from NIST were unavailable and MATLAB was used to fit polynomial curves to data from IAPWS (symbolized by red stars in Figure 2.4). In this manner, extrapolation of the water/steam properties to the necessary $1,700 \mathrm{~K}$ was achieved. Details regarding these polynomial curve fits may be found in Table 2.4:

Table 2.4: Order and range of polynomial curve fits used to extrapolate water/steam properties from $1,275 \mathrm{~K}$ to $1,700 \mathrm{~K}$.

\begin{tabular}{|c|c|c|}
\hline Property & Polynomial Order & Temperature Range \\
\hline Density & Quintic & $1,275 \mathrm{~K}$ to $1,700 \mathrm{~K}$ \\
\hline Heat Capacity & Quadratic & $1,275 \mathrm{~K}$ to $1,700 \mathrm{~K}$ \\
\hline Thermal Conductivity & Linear & $1,275 \mathrm{~K}$ to $1,700 \mathrm{~K}$ \\
\hline
\end{tabular}

One important caveat should be issued regarding the thermal conductivity data. Because neither the NIST nor IAPWS websites had conductivity data available for temperatures over $1,275 \mathrm{~K}$, a linear relationship was used to extrapolate beyond 1,275 $\mathrm{K}$ to the required $1,700 \mathrm{~K}$. This approach would appear to be valid, as both NIST and IAPWS conductivity values in the vicinity of (but not exceeding) $\mathrm{T}=1,275 \mathrm{~K}$ are very nearly linearly related to temperature. 
The data presented in Figure 2.4 were exported to VrSuite's material library in tabular format. When utilized in conjunction with the computed temperature distributions, the appropriate water/steam properties were extracted from the tables at each time-step for use in calculating the thermal conductance across each interface. Specifically, this was done by interpolation (between nodes) to calculate the temperature and corresponding fluid properties at the Gauss point of the contact element. In turn, this facilitated computation of an average contact conductance at the centroid of the element which was updated at each time-step.

In general, the thermal conductivities of the Zirconium alloy pressure tube, YSZ insulator and flow tube, and stainless steel liners and fuel cladding were temperaturedependent. These values, supplied by $\mathrm{AECL}^{3}$, are illustrated in Figure 2.5:

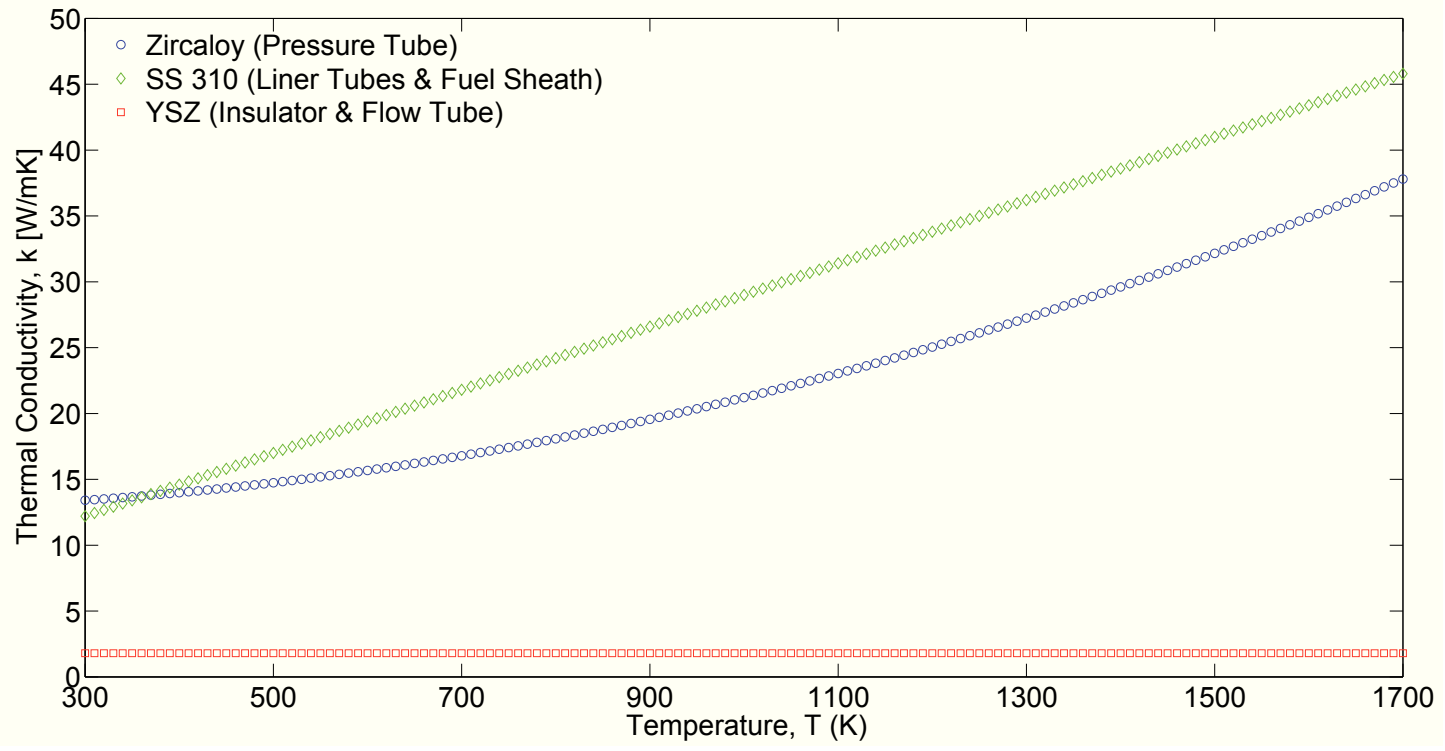

Figure 2.5: Thermal conductivity as a function of temperature for the fuel channel components.

\footnotetext{
${ }^{3}$ Verified using independent sources [16][17].
} 
Note that uncertainties were not provided for the thermal conductivity data presented in Figure 2.5, and thus were not examined in this thesis.

Experimental data and a correlation were also identified for the thermal conductivity and constant pressure specific heat capacity, respectively, of the Thorium Oxide fuel [18][19]. These data were compiled in VrSuite's material library and may be found in the papers cited previously.

\subsubsection{Stress Analysis}

Temperature-dependent mechanical properties were provided by $\mathrm{AECL}^{3}$, and are summarized below in Figure 2.6:
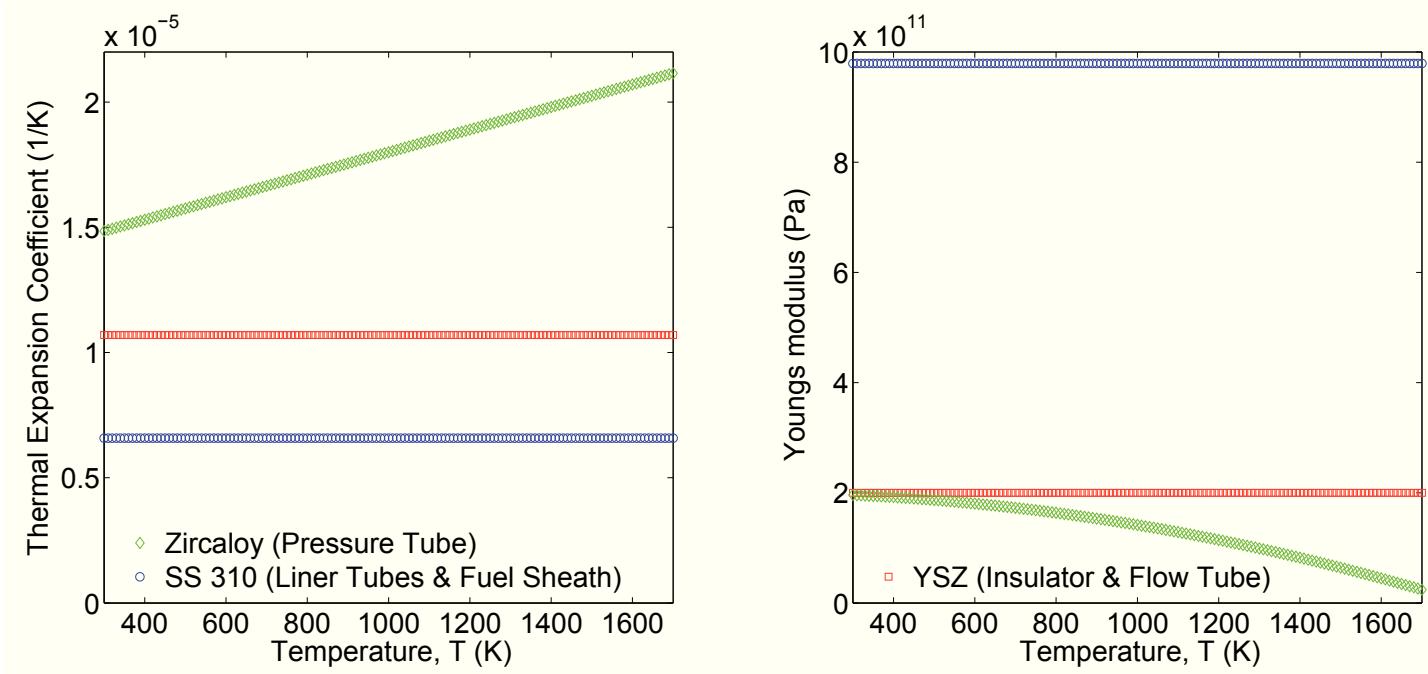

Figure 2.6: Thermal expansion coefficient (left) and Young's modulus (right) as functions of temperature for the fuel channel components.

Again, uncertainties were unavailable for the data plotted above and therefore were not studied in this thesis.

Poisson's ratio was assumed to be independent of temperature, and thus was given a constant value of $\nu=0.33$ for all materials. 


\subsection{Initial Conditions}

The start-up procedure for the Canadian SCWR entails a slow "ramping-up" of the coolant and moderator temperatures/pressures from an initial state to the normal operating conditions detailed in Table 2.5. Specifically, the initial ambient coolant temperature of $300 \mathrm{~K}$ is gradually increased to $625 \mathrm{~K}$ over a 50 hour interval [20]. However, the steady-state temperature and displacement fields were the only outputs of interest in the normal operation analysis (see the final paragraph of this section for details). Thus, a near-asymptotic increase was utilized in the ambient coolant/moderator temperatures from the initial $300 \mathrm{~K}$ to the state illustrated in Table 2.5. This distinction enabled the simulation duration to be compressed from $180,000 \mathrm{~s}$ to $400 \mathrm{~s}$.

In addition, a uniform temperature of $363 \mathrm{~K}$ was used to initialize the solid domain in normal operation, the rationale for this selection being explained in section 2.6.1 Thermal Analysis - Normal Operation. From the initial conditions illustrated in this paragraph and the previous one, the simulation was permitted to progress to steady-state.

For the LOCA scenario analyses, the steady-state temperature distributions and component deformations under normal operation were used as an initial state. 


\subsection{Boundary Conditions}

\subsubsection{Thermal Analysis - Normal Operation}

The coolant and moderator conditions (for very thin cross-sections near the bottom and top of the fuel channel) during normal operation have been summarized as follows in Table 2.5:

Table 2.5: Coolant and moderator conditions near the bottom and top of the fuel channel during normal operation.

\begin{tabular}{|c|c|c|}
\cline { 2 - 3 } \multicolumn{1}{c|}{} & Bottom & Top \\
\hline Ambient Coolant Temperature & $350{ }^{\circ} \mathrm{C}$ & $625{ }^{\circ} \mathrm{C}$ \\
\hline Coolant Pressure & \multicolumn{2}{|c|}{$25 \mathrm{MPa}$} \\
\hline Coolant Flow Rate & \multicolumn{2}{|c|}{$3.9 \mathrm{~kg} / \mathrm{s}$} \\
\hline Ambient Moderator Temperature & \multicolumn{2}{|c|}{$80{ }^{\circ} \mathrm{C}$} \\
\hline Moderator Pressure & $350 \mathrm{kPa}$ & $300 \mathrm{kPa}$ \\
\hline
\end{tabular}

It is important to note that while all VrSuite simulations were conducted on a thin cross-section near the top of the fuel channel, the state properties at the bottom were also required in order to estimate the boundary conditions averaged over the full $5 \mathrm{~m}$ length of the fuel channel.

The moderator pressure at the bottom of the assembly, $P_{m, b}=350 \mathrm{kPa}$ as seen in the table above, was derived from the hydrostatic pressure equation:

$$
P_{m, b}=P_{m, t}+\rho_{m} g L
$$

Heat exchange between the downward flowing coolant and inner surface of the flow tube was estimated via the Dittus-Boelter equation [8] for forced convection:

$$
h_{F T, I D}=\frac{k_{c}}{D_{F T, I D}}\left(0.023 \operatorname{Re}_{D_{F T, I D}}^{4 / 5} \operatorname{Pr}^{2 / 5}\right)
$$


For simplicity, the ambient coolant temperatures between the top and bottom of the inner flow tube were assumed to remain constant. This assumption was justified by the insulating properties of the YSZ flow tube, which afforded a large thermal resistance between the coolant water inside and the fuel bundle.

In the annular region bounded by the outside of the flow tube and inside of the inner liner, the Dittus-Boelter equation was employed again to estimate the convective heat transfer to the coolant. Equation (2.15) was modified slightly to yield the following:

$$
h_{\text {Annulus }}=\frac{k_{c}}{D_{h}}\left(0.023 \operatorname{Re}_{D_{h}}^{4 / 5} \operatorname{Pr}^{2 / 5}\right)
$$

Where the hydraulic diameter, $D_{h}$, is simply the difference in diameters of the inner surface of the inner liner and outer surface of the flow tube. $h_{\text {Annulus }}$ was applied to both of the aforementioned surfaces.

Heat transfer between the upward flowing coolant and fuel bundle was modelled once again by the Dittus-Boelter equation for forced convection:

$$
h_{F u e l}=\frac{k_{c}}{D_{F S}}\left(0.023 \operatorname{Re}_{D_{F S}}^{4 / 5} \operatorname{Pr}^{2 / 5}\right)
$$

A rudimentary technique was utilized to approximate $h_{F u e l}$, wherein the heat transfer coefficient was computed for a typical fuel pin using Equation (2.17) and subsequently applied to all 64 pins. This simplification necessitated the assumption that there was no interaction between the boundary layers of the 64 fuel pins (i.e, the spacing between pins was sufficiently large). Future research may strive to improve upon this approach via CFD simulations, which would grant a more accurate representation of spatial variations in $h_{F u e l}$.

For Equations (2.15)-(2.17), the coolant properties were determined using the 
mean bulk fluid temperature (i.e, the arithmetic average of the bottom and top ambient coolant temperatures). In conjunction with the data presented in Table 2.5, the length-averaged forced convection heat transfer coefficients were calculated:

- $h_{F T, I D}=6,102 \mathrm{~W} / \mathrm{m}^{2} \cdot \mathrm{K}$

- $h_{\text {Annulus }}=2,341 \mathrm{~W} / \mathrm{m}^{2} \cdot \mathrm{K}$

- $h_{\text {Fuel }}=3,263 \mathrm{~W} / \mathrm{m}^{2} \cdot \mathrm{K}$ and $3,230 \mathrm{~W} / \mathrm{m}^{2} \cdot \mathrm{K}$ for the inner and outer fuel rings, respectively.

Heat generation due to nuclear fission in the fuel pellets was modelled by a uniform thermal flux acting on the inner surfaces of the 64 fuel sheaths. This thermal flux was calculated as follows:

$$
q_{\text {Sheath }}=\frac{Q_{0}}{2 \pi r_{F S} L}
$$

Where the inner sheath radii, $r_{F S}$, for the inner and outer fuel rings may be found in Table 2.2. In its current design iteration, the nominal power generated by the Canadian SCWR is $Q_{0}=2,540 \mathrm{MW}_{t h}$. To convert this quantity to a power generated "per fuel pin", the nominal power was divided by the total number of fuel pins in the reactor (64 pins in each of the 336 fuel channels), which yielded a pin heating rate of $Q_{0}=118 \mathrm{~kW} /$ pin. Consequently, thermal fluxes of $q_{\text {Sheath }}=885 \mathrm{~kW} / \mathrm{m}^{2} /$ pin and $836 \mathrm{~kW} / \mathrm{m}^{2} /$ pin were computed for the inner and outer fuel rings, respectively.

Churchill and Chu's correlation [21] for free convection on a vertical wall was utilized at the outside of the pressure tube to simulate heat transferred to the moderator under buoyant action:

$$
h_{P T, O D}=\frac{k_{m}}{L}\left[0.825+\frac{0.387 R a_{L}^{1 / 6}}{\left(1+(0.492 / P r)^{9 / 16}\right)^{4 / 9}}\right]^{2}
$$


With $R a_{L}$ defined as follows:

$$
R a_{L}=G r_{L} \operatorname{Pr}=\frac{g \eta c_{p, m} \rho_{m}^{2}}{\mu_{m} k_{m}}\left(T_{s, P T}-T_{\infty, m}\right) L^{3}
$$

Where the moderator volumetric thermal expansion coefficient, $\eta$, was approximated in this investigation as $\eta\left(T_{f}\right)=-3.99 e^{-8} \cdot T_{f}^{2}+1.22 e^{-5} \cdot T_{f}-5.51 e^{-5}$; a polynomial curve fitted to data tabulated in [22]. Note that the ambient moderator temperature was assumed to remain constant at $80{ }^{\circ} \mathrm{C}$ for the entire duration of the normal operation analyses.

When Equations (2.19) and (2.20) are considered, it is apparent that the moderator-side heat transfer coefficient depends strongly upon the outer surface temperature of the pressure tube, both through the Rayleigh number and moderator fluid properties ${ }^{4}$ which must be evaluated at the film temperature. Since this pressure tube surface temperature is unknown a priori, the heat transfer coefficient must be re-calculated at each time-step using the surface temperature from the preceding time-step. In VrSuite, this was done by expressing Equation (2.19) as a polynomial function of the surface temperature. The polynomial was generated by fitting a curve to Churchill and Chu's correlation over a surface temperature range of $363 \mathrm{~K}-445$ $\mathrm{K}$, as is shown in Figure 2.7:

\footnotetext{
${ }^{4}$ Fluid properties for the heavy-water moderator were taken from NIST's correlations for $\mathrm{H}_{2} \mathrm{O}$ [13]; a reasonable approach as $\mathrm{D}_{2} \mathrm{O}$ (Deuterium oxide) is sufficiently similar in chemical composition, and thus yields similar thermal properties [23].
} 


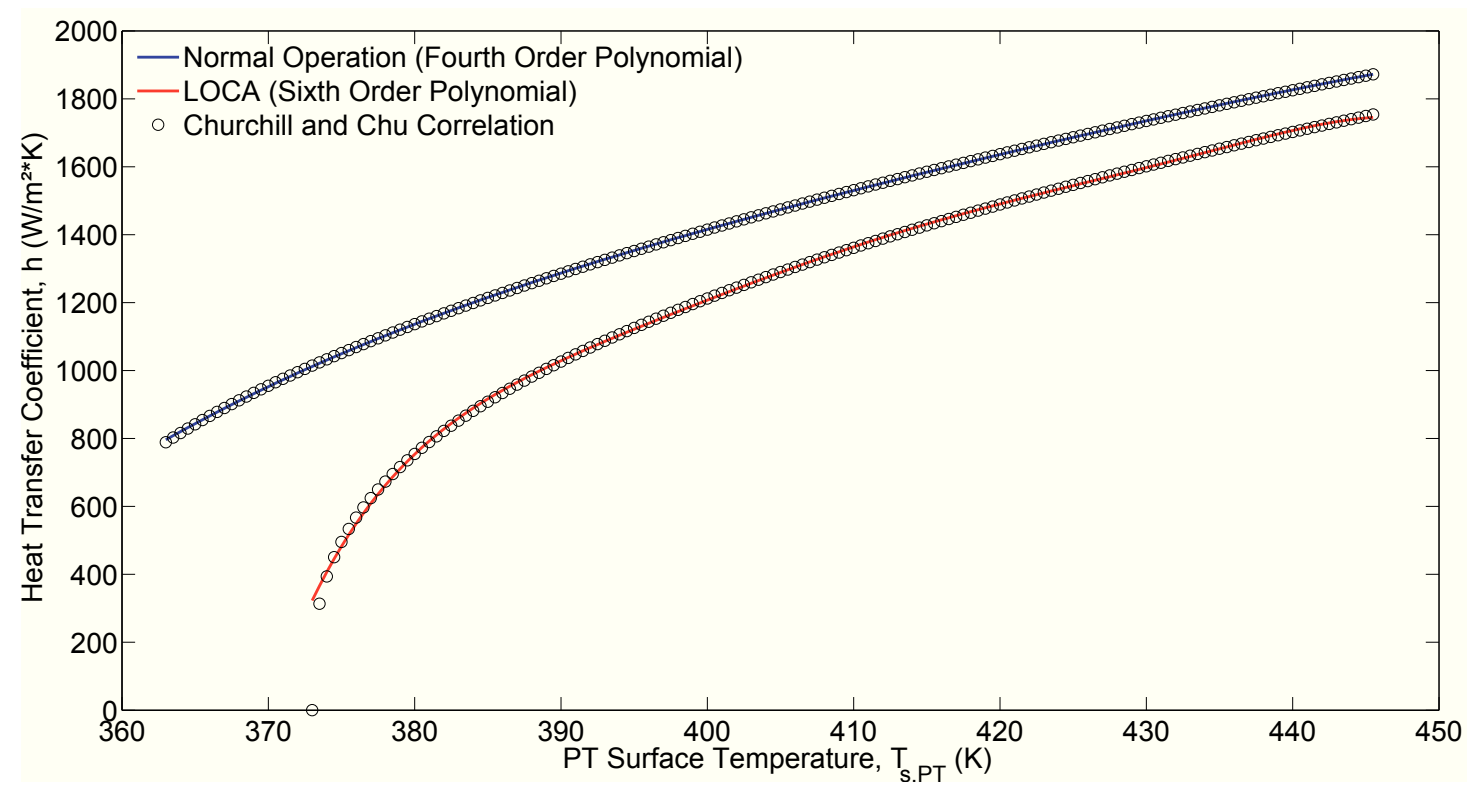

Figure 2.7: Heat transfer coefficient versus pressure tube surface temperature using Churchill and Chu's correlation for free convection on a vertical tube. The fitted quartic and sextic polynomials for normal operation and LOCA conditions, respectively, are also shown.

Worthy of note is the seemingly arbitrary selection for the lower temperature bound (i.e, $\mathrm{T}_{s, P T}=363 \mathrm{~K}$ for normal operation). While a more intuitive option would be $\mathrm{T}_{s, P T}=353 \mathrm{~K}$, such that $\mathrm{T}_{s, P T}=\mathrm{T}_{\infty, m}$ and $R a_{L}=0$, this range yielded a particularly poor fit when compared with that seen in Figure 2.7. Thus, the entire domain was prescribed a uniform initial temperature of $363 \mathrm{~K}$ such that subsequent heat transfer coefficients would closely conform to Equation (2.19). This technique was not feasible for the LOCA case and will be discussed in section 2.6.2 Thermal Analysis - LOCA.

It also warrants mentioning that while it would be desirable to input Equation (2.19) into the software in place of an inexact polynomial, this step would require a multitude of subtle, yet complicated alterations to VrSuite's programming. 


\subsubsection{Thermal Analysis - LOCA}

During a LOCA, the supercritical water inventory within the coolant loop is quickly depleted. The resulting rapid decrease in power output of the fuel (assuming full insertion of the control rods) is accompanied by a significant increase in the cladding temperature. Therefore, when one considers the fourth-order proportionality of thermal radiation heat flux with surface temperature [24], it is conceivable that radiation will supersede forced convection as the primary heat transfer mechanism between the fuel bundle, flow tube, and inner liner. For this reason, it was imperative that this phenomenon be accurately simulated in order to properly assess the feasibility of the no-core-melt concept.

In order to understand the challenges inherent in modelling radiation heat exchange in the fuel channel, one should consider an energy balance on a surface (denoted by index $k$ ) of finite area within an $M$-surface enclosure:

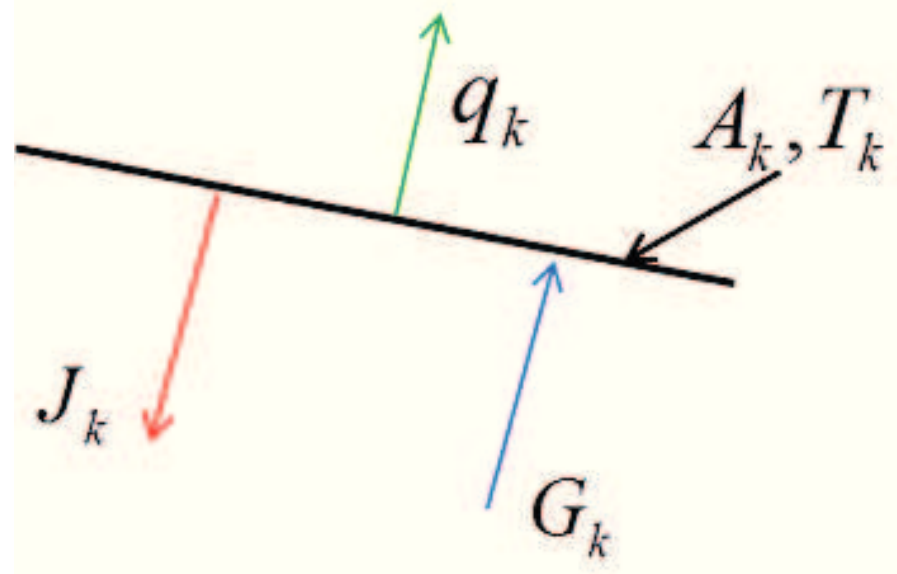

Figure 2.8: Energy balance on a surface of finite area, $A_{k}$.

In Figure 2.8, the net heat conducted away from surface $k, q_{k}$, is equal to the difference between the irradiance $\left(G_{k}\right)$ and radiosity $\left(J_{k}\right)$ :

$$
q_{k}=J_{k}-G_{k}
$$


Where $G_{k}$ may be defined as the radiant energy incident on surface $k$ that is reflected and emitted by all $M$ surfaces within the enclosure, or:

$$
G_{k}=\sum_{j=1}^{M} J_{k} F_{k-j}
$$

and $J_{k}$ is the radiation leaving surface $k$ in the form of reflected and emitted energy:

$$
J_{k}=\epsilon_{k} S T_{k}^{4}+\gamma_{k} G_{k}
$$

Equations (2.21)-(2.23) imply that the net heat conducted away from surface $k$ is a function of the temperatures and radiosities of all $M$ surfaces comprising the enclosure. Thus, it is necessary to solve a system of linear equations ${ }^{5}$ to compute $q_{k}$ for $k \in\{1,2, \cdots, M\}$, as shown:

$$
\sum_{j=1}^{M}\left(\frac{\delta_{k j}}{\epsilon_{j}}-F_{k-j} \frac{1-\epsilon_{j}}{\epsilon_{j}}\right) q_{j}=\sum_{j=1}^{M} F_{k-j} S\left(T_{k}^{4}-T_{j}^{4}\right)
$$

Six assumptions are inherent in Equation (2.24) which have been enumerated below:

- All surfaces are diffuse-grey.

- All surfaces are opaque.

- Emissivity is independent of temperature (i.e, $\epsilon=0.8$ in accordance with the research presented in [5]).

- Fluid medium is transparent to thermal radiation.

- Incident, reflected, and emitted radiation are uniform over the area of each discrete surface element.

- Temperature is uniform over the area of each surface element.

\footnotetext{
${ }^{5}$ Reference [24] may be consulted for a more exhaustive treatment of Equations (2.21)-(2.24).
} 
Furthermore, within the context of the Canadian SCWR fuel channel two significant challenges are encapsulated in Equation (2.24):

1. Analytical determination of the view factors between participating surfaces is difficult given the complex geometry entailed by the 64-pin fuel bundle.

2. Calculation of radiation heat exchange between all participating surfaces requires a known temperature field, yielding $2 M$ unknowns $\left(q_{k}\right.$ and $T_{k}$, with $k \in\{1,2, \cdots, M\})$ in $M$ equations.

To overcome the first of these obstacles, FEM software was utilized to evaluate the view factors numerically. Siemens NX 8.5/TMG [25] (henceforth abbreviated as "TMG" for the sake of brevity) was employed to model the surfaces of the flow tube, fuel cladding, and inner liner participating in thermal radiation heat exchange. These surfaces were then discretized in an identical manner to that described in section $\mathbf{2 . 3}$ Discretization, albeit with each surface element spanning the full $5 \mathrm{~m}$ length of the fuel channel. Care was taken to enforce similarity between the TMG and VrSuite element centroid co-ordinates (within precision) to avoid any incompatibility between the two models. A cross-section of the ensuing mesh may be seen in Figure 2.9:
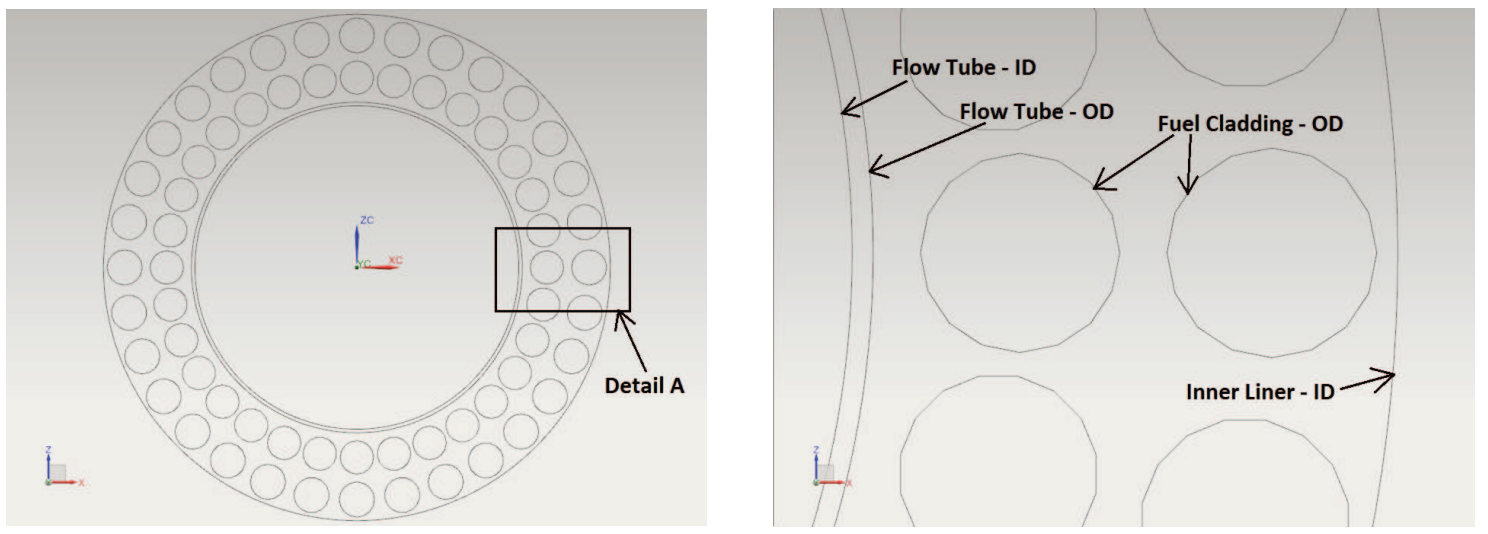

Figure 2.9: Top view (left) and detail view (right) of the flow tube, fuel cladding, and inner liner modelled in TMG. 
It is important to note that the $5 \mathrm{~m}$ fuel channel length was assumed to be sufficiently large relative to its radial dimension. This distinction implied that radiation escaping out of the top and bottom of the channel to the surroundings was negligible compared with that incident upon the participating surfaces. Furthermore, variations of the view factors with the displacements of the inner liner were considered to be negligible. This simplification averted convoluted coupling of the stress and view factor simulations.

Since the view factor is a purely geometric quantity, boundary conditions and fluid/material/optical properties were not required to compute $F_{k-j}$. Numerical simulation using a hemicube algorithm [25][26] generated view factors between pairs of elements, with occluded pairs (i.e, $F_{k-j}=0$ ) being omitted. For details regarding verification of the TMG software, Appendix E: Siemens NX 8.5/TMG Verification should be consulted.

An $M \times M$ view factor matrix was compiled with the following form:

$$
\mathbf{F}=\left[\begin{array}{cccc} 
& & & \\
F_{1-1} & F_{1-2} & \cdots & F_{1-M} \\
F_{2-1} & F_{2-2} & \cdots & F_{2-M} \\
\vdots & \vdots & \ddots & \vdots \\
F_{M-1} & F_{M-2} & \cdots & F_{M-M}
\end{array}\right]
$$

Worthy of mention is that the TMG software does not output view factors for reciprocal pairs of elements. For instance, if $F_{k-j}$ is printed to the TMG output file, then $F_{j-k}$ is considered to be superfluous and is not included. Since all view factors were necessary for closure of Equation (2.24), the reciprocal values were calculated from the following relation:

$$
A_{k} F_{k-j}=A_{j} F_{j-k}
$$


Also warranting remark is that the elements used in the TMG analyses were planar and thus unable to radiate heat to themselves. This in turn implied that the entries on the diagonal of the view factor matrix were zero (i.e, $F_{k-k}=0$ ).

With the view factor matrix assembled, the challenge remained of computing the net thermal fluxes, $q_{k}$, from the unknown temperature field, $T_{k}$. This obstacle was circumvented by coupling the thermal and radiation solvers together within the VrSuite FEM software, and will be addressed in section 2.7.1 Solver Coupling.

For simplicity, it was assumed that depletion of the entire coolant inventory occurred instantaneously at the onset of the LOCA (i.e, $t=0 \mathrm{~s}$ ), with a consequent cessation of all convective cooling of the fuel bundle. It should be noted that this process deviates significantly from reality, as coolant flow/boiling within the fuel channel immediately following a LOCA is highly complex and transient in general [4].

The coolant depletion described above was followed by deployment of the control rods, which transpired over the course of one second [4]. During this interval, nuclear fission in the fuel pellets continued with a resultant temperature increase of the cladding in the absence of coolant. Control rod deployment precipitated a rapid discontinuation of further fission reactions, ultimately leaving radioactive decay of the fission products as the sole mechanism of heat generation within the fuel pellets. In previous no-core-melt research performed by others, this time-dependent behaviour was approximated as follows [5][7]:

- Insertion of the control rods into the reactor core from $t=0 \mathrm{~s}$ (after onset of LOCA) to $t=1 \mathrm{~s}$. Channel power is nominal (i.e, $Q_{0}$ ) for the duration.

- Channel power reduction of $100 \%$ (of nominal power) to $7 \%$ from $t=1 \mathrm{~s}$ to t $=2 \mathrm{~s}$.

- Power remains constant at $7 \%$ from $t=2 \mathrm{~s}$ to $\mathrm{t}=20,000 \mathrm{~s}$. 
In the present study, the transient occurring between $\mathrm{t}=1 \mathrm{~s}$ and $2 \mathrm{~s}$ was modelled by an exponentially decaying curve. This curve was of the form:

$$
q_{\text {Sheath }}(t)=\frac{Q_{0}}{2 \pi r_{S} L} e^{-t / \tau}
$$

where the time constant, $\tau$, was determined to be $0.7024 \mathrm{~s}$. The thermal flux dictated by Equation (2.26) was applied to the inner surfaces of the fuel cladding as a boundary condition.

The moderator-side heat transfer coefficient was estimated in a similar manner as for normal operation, with the ambient moderator temperature being changed to a constant $\mathrm{T}_{\infty, m}=373 \mathrm{~K}$. This revised ambient temperature assumes proper functioning of the PMCS (Passive Moderator Cooling System) [3]; a safety feature devised by AECL to ensure that the moderator temperature is maintained below its boiling point in the event of an accident.

As is evident from Figure 2.7, a lower temperature bound of $\mathrm{T}_{s, P T}=\mathrm{T}_{\infty, m}=373$ $\mathrm{K}$ was specified for the LOCA scenario. This measure was taken to accommodate the anticipated steady-state pressure tube temperature of $\mathrm{T}_{\infty, m}$. The ensuing polynomial curve fit to Churchill and Chu's correlation may be observed in Figure 2.7. Worthy of remark is the significant discrepancy between the sextic LOCA polynomial and correlation in the vicinity of $\mathrm{T}_{s, P T}=373 \mathrm{~K}$; a consequence that was bypassed in the normal operation case by initializing the entire solid domain with a uniform temperature of $\mathrm{T}=363 \mathrm{~K}$. 


\subsubsection{Stress Analysis}

A stress simulation was performed for both normal operation and LOCA conditions, subject to the boundary conditions described in Figure 2.10:

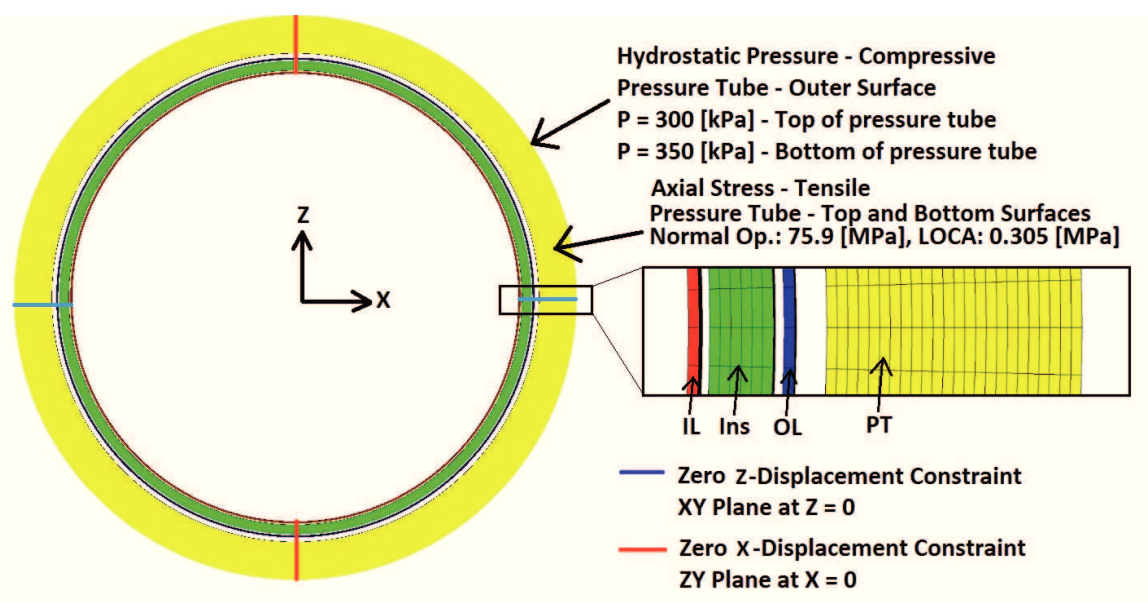

Figure 2.10: Boundary conditions used in the FEM stress analyses. Unless otherwise stated, a hydrostatic pressure of $25 \mathrm{MPa}$ (normal operation) or $100 \mathrm{kPa}$ (LOCA) acts on every surface. Not shown is the displacement constraint in the Ydimension imposed upon all of the bottom surfaces.

As is displayed in Figure 2.10, displacements were constrained to zero for all nodes lying in the $\mathrm{XY}$ and $\mathrm{ZY}$ planes at $\mathrm{Z}=0$ and $\mathrm{X}=0$, respectively. This measure was taken to ensure uniform radial deformations in each component; a consequence of the uniformly applied mechanical and thermal loads. Likewise, all nodes on the bottom surface of each component were constrained in the Y-dimension to restrain rigid body motion.

Tensile axial stresses were applied to the top and bottom surfaces of the pressure tube to simulate the hydrostatic pressure of the coolant acting on the end caps of the pressure tube. Pressures of $25 \mathrm{MPa}$ and $100 \mathrm{kPa}$ were applied to every surface, with the exception of the outer surface of the pressure tube. Here, a pressure of $300 \mathrm{kPa}$ was applied to simulate the hydrostatic pressure of the moderator. 


\subsection{Numerical Model}

\subsubsection{Solver Coupling}

Coupling of the FEM solvers was required to accurately capture the complicated interactions between phenomena. The procedure is depicted below in Figure 2.11:

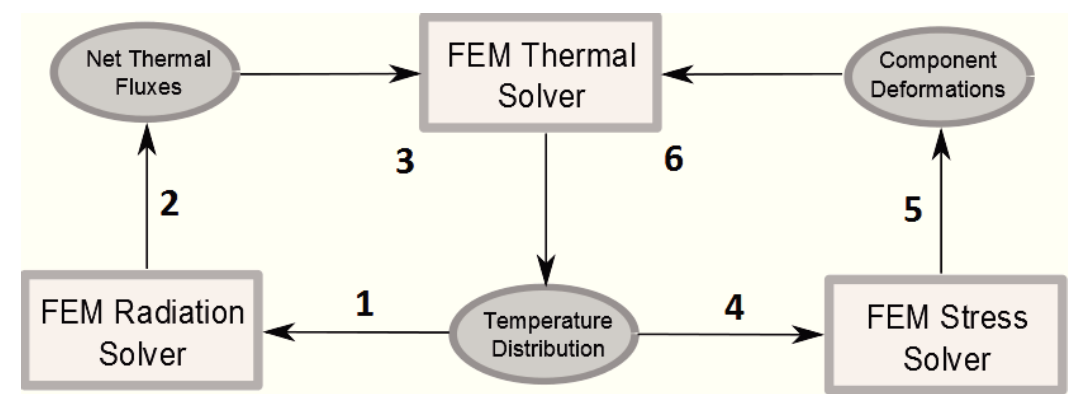

Figure 2.11: Data flow between the FEM thermal, radiation, and stress solvers at a typical time-step.

The flow of data illustrated in Figure 2.11 takes place within a single time-step $n$ and is ordered as follows:

1. Temperature field from the previous time-step is used to initialize the FEM radiation solver.

2. In conjunction with the view factors, the temperature field is used to calculate the net-thermal fluxes $q_{k}$, as per Equation (2.24).

3. Net-thermal fluxes are exported to the FEM thermal solver in the form of boundary conditions, whereby the temperature field is re-calculated via Equation (2.1).

4. Updated temperature field is used to initialize the FEM stress solver.

5. FEM stress solver computes the deformations of the components under combined thermal/mechanical loads. 
6. Resultant water gap dimensions are sent to the FEM thermal solver facilitating calculation of the thermal conductances and temperature fields.

The procedure described previously is repeated for all succeeding time-steps, with $n \in\{1,2, \cdots, N\})$.

However, it is perhaps sensible at this point to address one potential obstacle in the procedure described above. Namely, it is conceivable that when the channel components are subjected to large temperatures (and therefore, large thermal strains), two or more of them may come into close proximity. One may recall from Equation (2.8) that thermal conductance due to conduction exhibits an inversely proportional relationship with the gap width. Thus, in the event that two components do come into close proximity, the thermal conductance may become unbounded (physically, this means the difference in temperatures $\mathrm{T}^{+}-\mathrm{T}^{-} \rightarrow 0$ ). To avert this possibility, a "maximum conductance" has been implemented into VrSuite, as is explained in Figure 2.12 below:

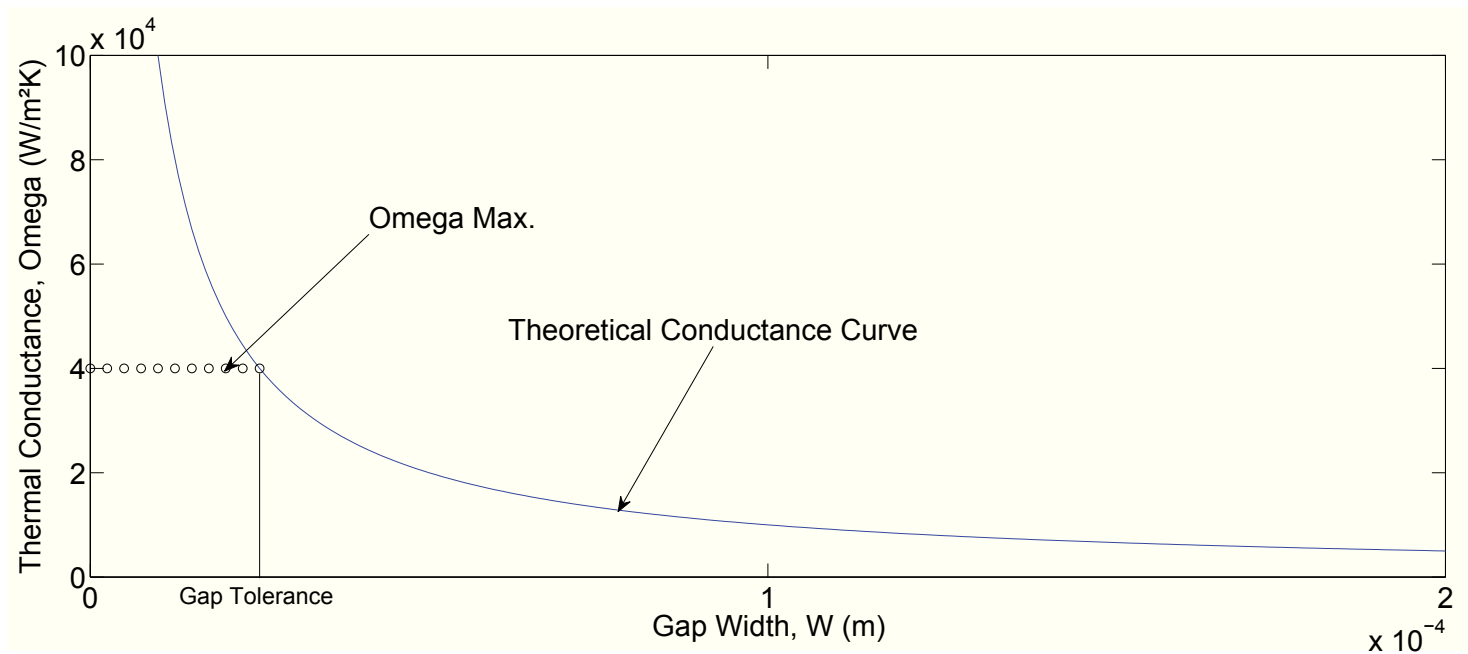

Figure 2.12: Demonstration of the maximum conductance concept used to avoid unboundedness for thin water gaps. This particular example utilizes a maximum conductance of $\Omega_{M a x}=40,000 \mathrm{~W} / \mathrm{m}^{2} \cdot \mathrm{K}$ and thermal conductivity of $\mathrm{k}=1.0$ $\mathrm{W} / \mathrm{m} \cdot \mathrm{K}$. 
When the gap contracts to the threshold gap tolerance seen in Figure 2.12, the thermal conductance is re-assigned the value $\Omega_{\text {Max }}$ for all deformations with gap width less than the gap tolerance. This allows the simulation to progress without the thermal conductances and fluxes becoming unbounded.

\subsubsection{Simulation Parameters}

In the normal operation thermal/stress simulation described in this thesis, a sufficiently long duration was selected to allow the transient solution to decay to zero, leaving the steady-state temperature and displacement distributions. This selected duration, as well as the resulting global maximum temperature and displacement changes in the final time-step (i.e, $\Delta T_{\text {Max }}^{N}=\left|T_{\text {Max }}^{N}-T_{\text {Max }}^{N-1}\right|$ and $\Delta u_{\text {Max }}^{N}=\left|u_{\text {Max }}^{N}-u_{\text {Max }}^{N-1}\right|$ ), have been summarized in Table 2.6:

Table 2.6: Normal operation analysis duration and temperature/displacement changes at the final $\left(N^{t h}\right)$ time-step.

\begin{tabular}{|c|c|}
\hline Simulation Parameter & Quantity \\
\hline Duration $(\mathrm{s})$ & 400 \\
\hline$\Delta T_{\text {Max }}^{N}(K)$ & $1.13 \mathrm{e}-3$ \\
\hline$\Delta u_{\text {Max }}^{N}(m)$ & $1.24 \mathrm{e}-9$ \\
\hline
\end{tabular}

It is apparent from the table above that, when used in conjunction with a time-step of $\Delta t=1.0 \mathrm{~s}$, the selected simulation duration was sufficient to ensure that the normal operation solution attained a steady-state.

In accordance with the exponentially decaying channel power dictated by Equation (2.26), large temperature changes are expected immediately after the onset of a LOCA. Thus, an initially small time-step is required to accurately resolve this transient without succumbing to numerical instability. However, in the latter stages of the accident (i.e, $\mathrm{t}=20,000 \mathrm{~s}$ ), the temperature rate of change with time approaches 
zero and larger time-steps may be used in order to improve numerical accuracy and reduce the simulation CPU time. Therefore, in contrast with the constant time-step size described prior for normal operation, the LOCA analyses employed an exponential time-stepping technique wherein the current time-step size was calculated as shown:

$$
\Delta t^{n}=\Delta t^{1} a^{(n-1)}
$$

For the analyses presented in this thesis, parameters of $\Delta t^{1}=0.1 \mathrm{~s}$ and $\mathrm{a}=1.01$ afforded a desirable combination of small time-steps at the onset of LOCA and large time-steps toward the end of the accident. Appendix A: Time-Step Dependency Study may be consulted for more details. 


\section{Chapter 3}

\section{Results \& Discussion}

By analyzing an alternate fuel channel configuration using similar methods to those of the reference design explored in Chapter Two, it was possible to study the variations in heat transfer evoked by changes in fuel channel design. In the future, the results presented here may be extrapolated by way of an optimization study, the concept for which has been outlined in Appendix F: Fuel Channel Design Optimization. In the alternate design, gaps one and two were assumed zero and gap three was given a $0.5 \mathrm{~mm}$ width. The dimensions of the flow tube and fuel bundle were left unchanged (see Tables 2.1 and 2.2), while the remaining component sizes were as follows:

Table 3.1: Dimensions of the alternate fuel channel design.

\begin{tabular}{|c|c|c|}
\hline Component & Inner Radius $(\mathrm{mm})$ & Outer Radius $(\mathrm{mm})$ \\
\hline Inner Liner & 72.0 & 72.5 \\
\hline Gap One & 72.5 & 72.5 \\
\hline Insulator & 72.5 & 72.9 \\
\hline Gap Two & 72.9 & 72.9 \\
\hline Outer Liner & 72.9 & 73.2 \\
\hline Gap Three & 73.2 & 73.7 \\
\hline Pressure Tube & 73.7 & 83.7 \\
\hline
\end{tabular}




\subsection{Maximum Cladding Surface Temperature}

As the primary objective of the no-core-melt safety feature is to limit the fuel cladding to sub-melting temperatures (i.e, below $1,450{ }^{\circ} \mathrm{C}$ for stainless steel [4]) during a LOCA, the fuel cladding temperatures over the full 20,000 s accident duration were examined. The temperatures at the outer surface of a typical inner ring fuel sheath were plotted against time, with the inner fuel ring being selected given the generally higher temperatures here when compared with the outer fuel ring. The results have been illustrated below in Figure 3.1:

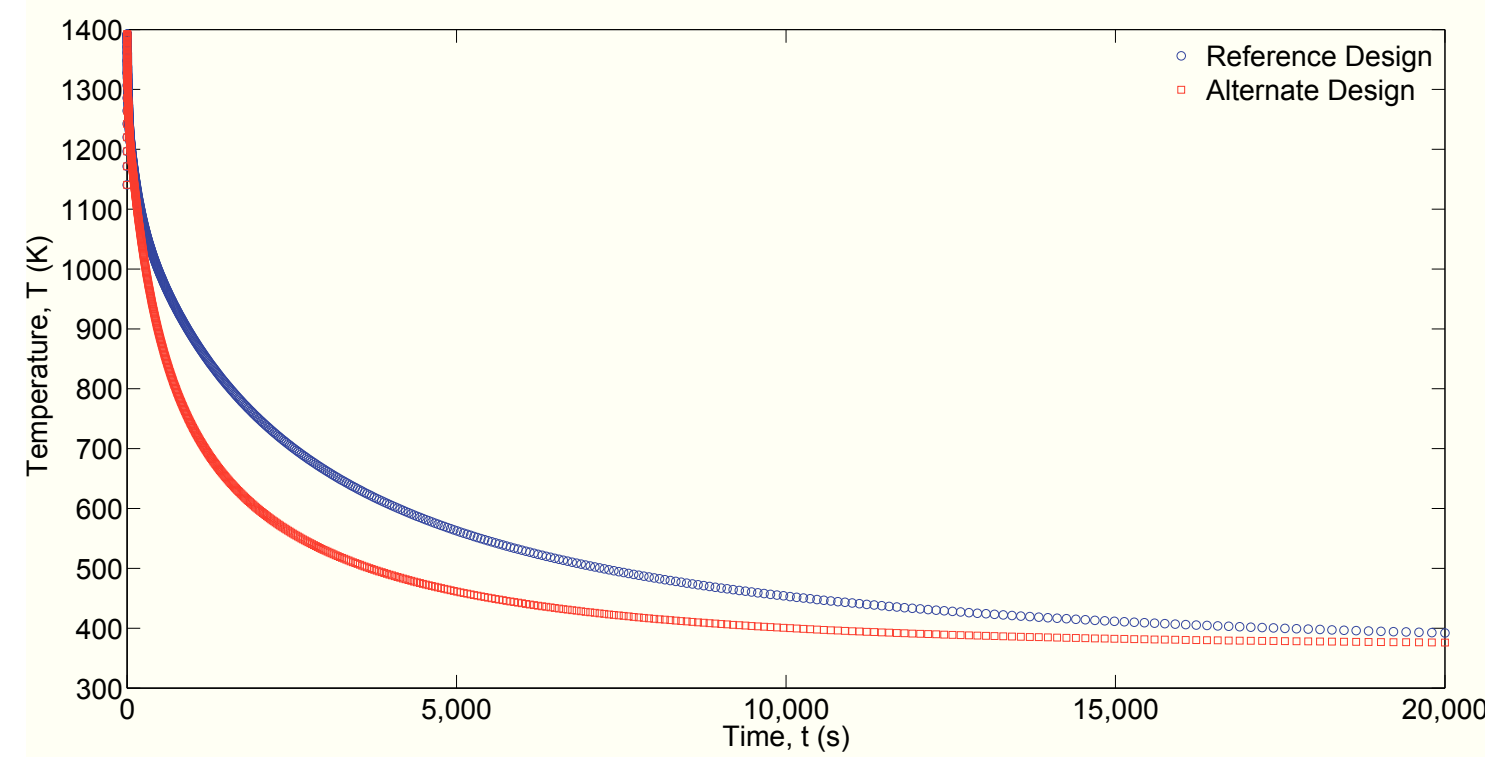

Figure 3.1: Inner fuel ring cladding temperatures for the entire 20,000 s LOCA duration.

It is evident from Figure 3.1 that there is significant deviation between cladding temperatures of the reference and alternate fuel channel designs in the latter stages of the LOCA (i.e, $t>60 \mathrm{~s}$ ). In general, it appears that the alternate design cools to the ambient moderator temperature $\left(\mathrm{T}_{\infty, m}=373 \mathrm{~K}\right)$ at a comparatively faster rate. This pattern likely resulted from the markedly different water gap dimensions between the two variants. For easy reference, these dimensions have been reprinted 
in Table 3.2:

Table 3.2: Water gap dimensions for the reference and alternate fuel channel designs.

\begin{tabular}{|c|c|c|}
\cline { 2 - 3 } \multicolumn{1}{c|}{} & Reference Design & Alternate Design \\
\hline Gap One & $0.5 \mathrm{~mm}$ & $0 \mathrm{~mm}$ \\
\hline Gap Two & $0.5 \mathrm{~mm}$ & $0 \mathrm{~mm}$ \\
\hline Gap Three & $1.5 \mathrm{~mm}$ & $0.5 \mathrm{~mm}$ \\
\hline
\end{tabular}

The water gap dimensions seen above have important implications when heat transfer through the fuel channel is considered. As per Equation (2.8):

$$
\Omega_{C o n d}=\frac{k_{G}}{W}
$$

The magnitude of the heat conducted across these gaps is inversely proportional to their widths. Thus, it is conceivable that the gap dimensions unique to each design will garner significant differences in heat transfer characteristics.

As anticipated, the large radial temperature gradient accompanying the LOCA resulted in significant deformations in the liner tubes, insulator, and pressure tube. This phenomenon is highly desirable as sufficiently large thermal expansions will bring two or more components into physical contact, in turn causing heat to transfer more effectively through the mating asperities of the two surfaces (see section 2.7.1 Solver Coupling for a description of how this phenomenon is currently modelled by the FEM software).

However, due to the large water gaps employed by the reference design fuel channel, only the inner liner and insulator were able to make physical contact during the course of the LOCA, with the second and third gaps remaining open for the duration. By contrast, the initially closed first water gap in the alternate design remained closed for the entirety of the accident, with the third gap also closing between $t=3$ 
$\mathrm{s}$ and $246 \mathrm{~s}$. Thus, the alternate fuel channel configuration was able to exploit the comparatively large heat transfer rates afforded by the smaller and/or closed gaps, resulting in a faster cooling rate relative to the reference design.

However, it is also prudent to closely study the behaviour immediately after the onset of the LOCA in the vicinity of the global maximum cladding temperature. To this effect, the first sixty seconds depicted in Figure 3.1 have been plotted below in Figure 3.2:

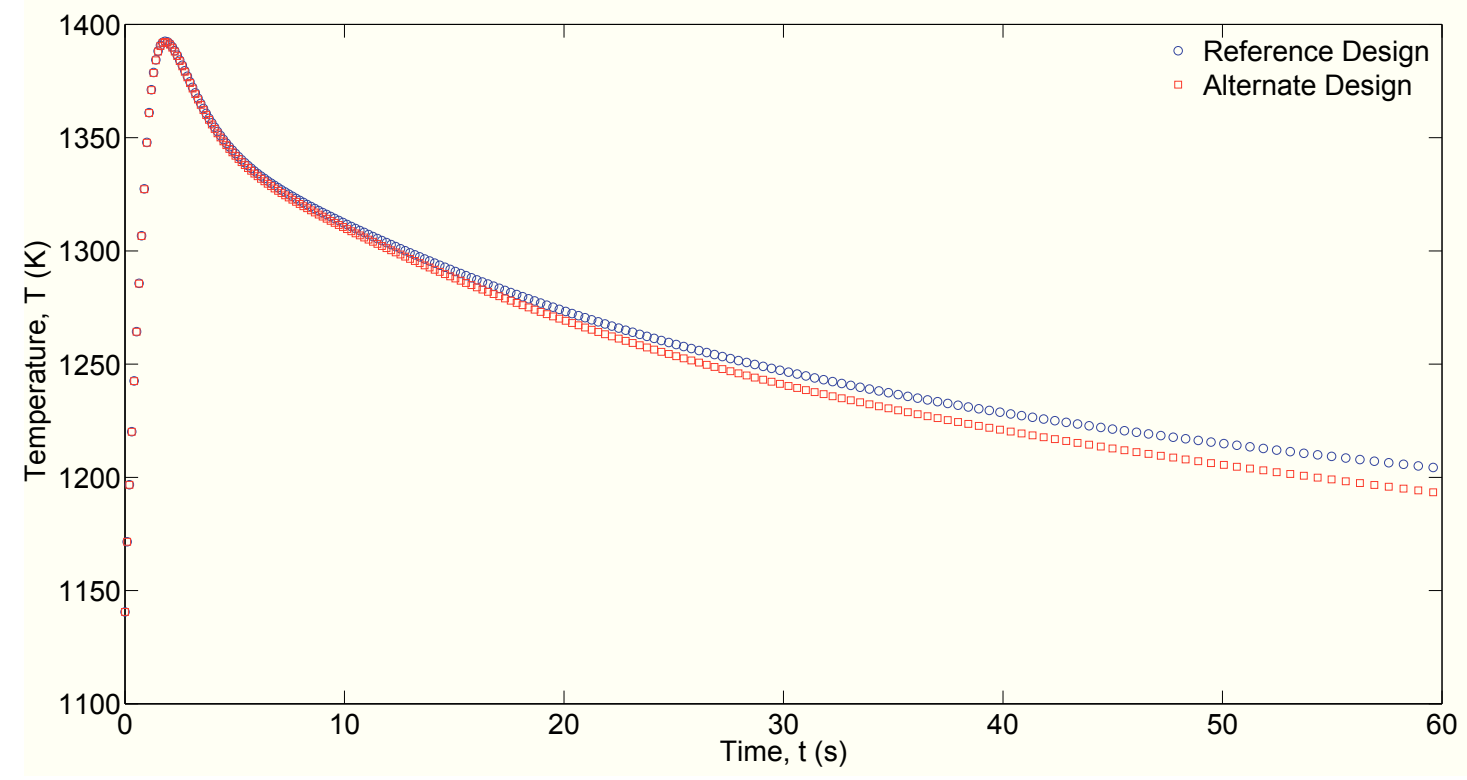

Figure 3.2: Inner fuel ring cladding temperatures for the first $60 \mathrm{~s}$ following the onset of the LOCA.

It is apparent from Figure 3.2 that both fuel channel configurations yield sub-melting temperatures for the first $60 \mathrm{~s}$ (and by extension, the entire 20,000 s duration as well). However, it may also be observed that there is a negligible difference between the cladding temperatures attained by the two designs immediately following the onset of the LOCA. Specifically, the global maximum temperatures obtained at approximately $\mathrm{t}=1.8 \mathrm{~s}$ elicited a percent difference of $0.022 \%$ between the reference and alternate fuel channel configurations. This result would suggest that variations in the fuel 
channel component dimensions will yield only minimal differences in the maximum LOCA fuel cladding temperatures. Therefore, it is plausible that some other metric may grant better insight into the relationship between the fuel channel design and its heat transfer characteristics. One such alternative will be explored in Section 3.2.

The trend observed in Figure 3.2 likely resulted from the highly dynamic behaviour in the first seconds following the LOCA. In order to gain further insight into this behaviour, the temperatures encountered by the inner surfaces of the liner tubes, insulator, and pressure tube in the first $1.8 \mathrm{~s}$ following the LOCA have been plotted below in Figure 3.3. Note that this $1.8 \mathrm{~s}$ interval is simply the time that transpires between the beginning of the LOCA and the global maximum cladding surface temperature:
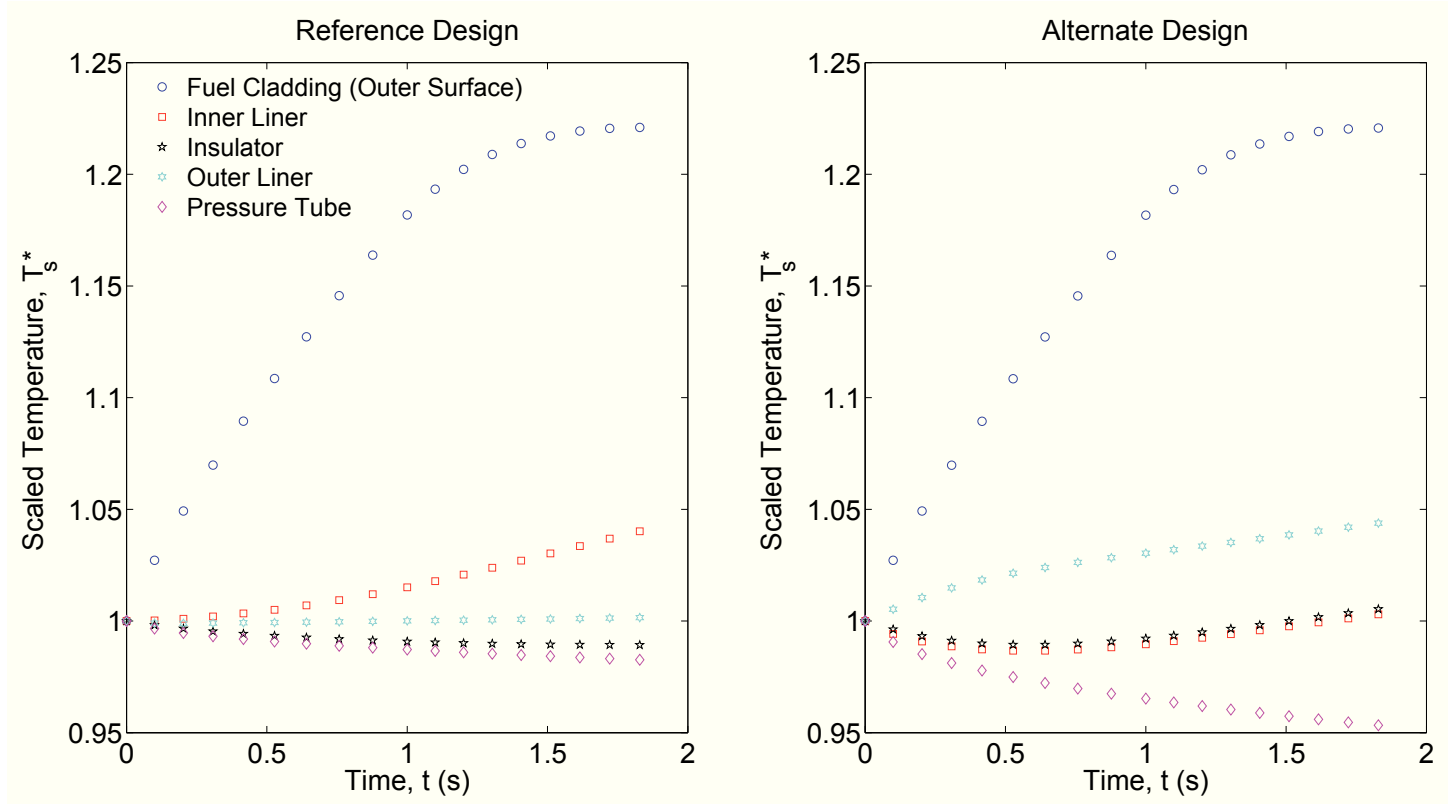

Figure 3.3: Scaled temperature versus time at the outer surface of the fuel cladding and inner surfaces of the liners, insulator, and pressure tube. Temperatures are scaled as per Equation (3.1). 
Where the scaled surface temperatures seen in Figure 3.3 were computed via division by the initial temperature at each surface as shown:

$$
T_{s}^{*}(t)=\frac{T_{s}(t)}{T_{s}(t=0 s)}
$$

When the left-hand plot of Figure 3.3 is considered, it is apparent that the surface temperatures of the reference design fuel cladding and inner liner increase over the interval $\mathrm{t}=[0,1.8] \mathrm{s}$, whereas the remaining component surfaces decrease in temperature. This trend would suggest that the dominant heat transfer mechanism in the latter components is conduction between their respective inner and outer surfaces. In turn, this phenomenon would suggest that only a small proportion of the energy radiated from the fuel bundle to inner liner has propagated to the outermost components; a plausible conjecture given the prohibitively short time interval.

Examination of the alternate fuel channel design (the right-hand plot of Figure 3.3) surface temperatures reveal similar peculiarities. Specifically, the concavity of the inner liner and insulator temperatures imply that the heat radiated from the fuel bundle is rapidly conducted through these two mating components after a brief delay. However, this trend is not transmitted to the outer liner and pressure tube as the second water gap separating them from the insulator appears to impede this radiant energy from further propagation.

The previous two paragraphs attest that the dual effects of a short time interval and thermally resistant water gaps deter the flow of heat between the fuel and moderator. In other words, over the $1.8 \mathrm{~s}$ that transpire between the onset of the LOCA and the global maximum cladding temperature, only a small proportion of the heat radiated by the fuel is conducted towards the moderator. Thus, it may be concluded that variations in the geometry of the liners, insulator, and pressure tube will yield only marginal affects upon the MCST attained during the accident. 


\subsection{Fuel Channel Efficiency}

Although the global maximum fuel cladding temperature described in the previous section is generally regarded as the foremost measure of no-core-melt feasibility, valuable conclusions may also be drawn by studying the rates of LOCA heat rejection. In particular, the net-thermal flux conducted away from the inner surface of the inner liner may be calculated via Equation (2.24). Furthermore, these inner liner fluxes may be non-dimensionalized by the corresponding flux under normal operating conditions at steady-state:

$$
q^{*}(t)=\frac{q_{L O C A}(t)}{q_{\text {Normal }, S-S}}
$$

Where the normal operation flux from Equation (3.2) is simply the rate of heat convected from the inner liner by the supercritical water coolant:

$$
q_{\text {Normal }, S-S}=h_{\text {Annulus }}\left(T_{I L, S-S}-T_{\infty, c}\right)
$$

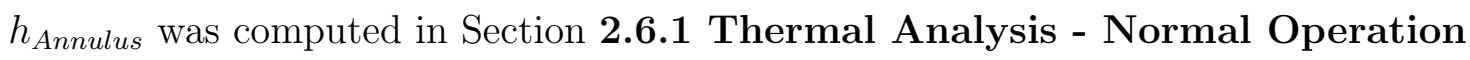
to have a value of $2,341 \mathrm{~W} / \mathrm{m}^{2} \cdot \mathrm{K}$, and $T_{I L, S-S}=877 \mathrm{~K}$ and $820 \mathrm{~K}$ for the reference and alternate fuel channel designs, respectively.

Efficient fuel channel designs tend to minimize heat loss from the fuel channel during normal operation while maximizing heat rejection during a LOCA. Therefore, examination of the behaviour of $q^{*}$ with time should enable an understanding of the performance of the two designs under consideration. In that vein, the time variation of $q^{*}$ is illustrated in Figure 3.4: 


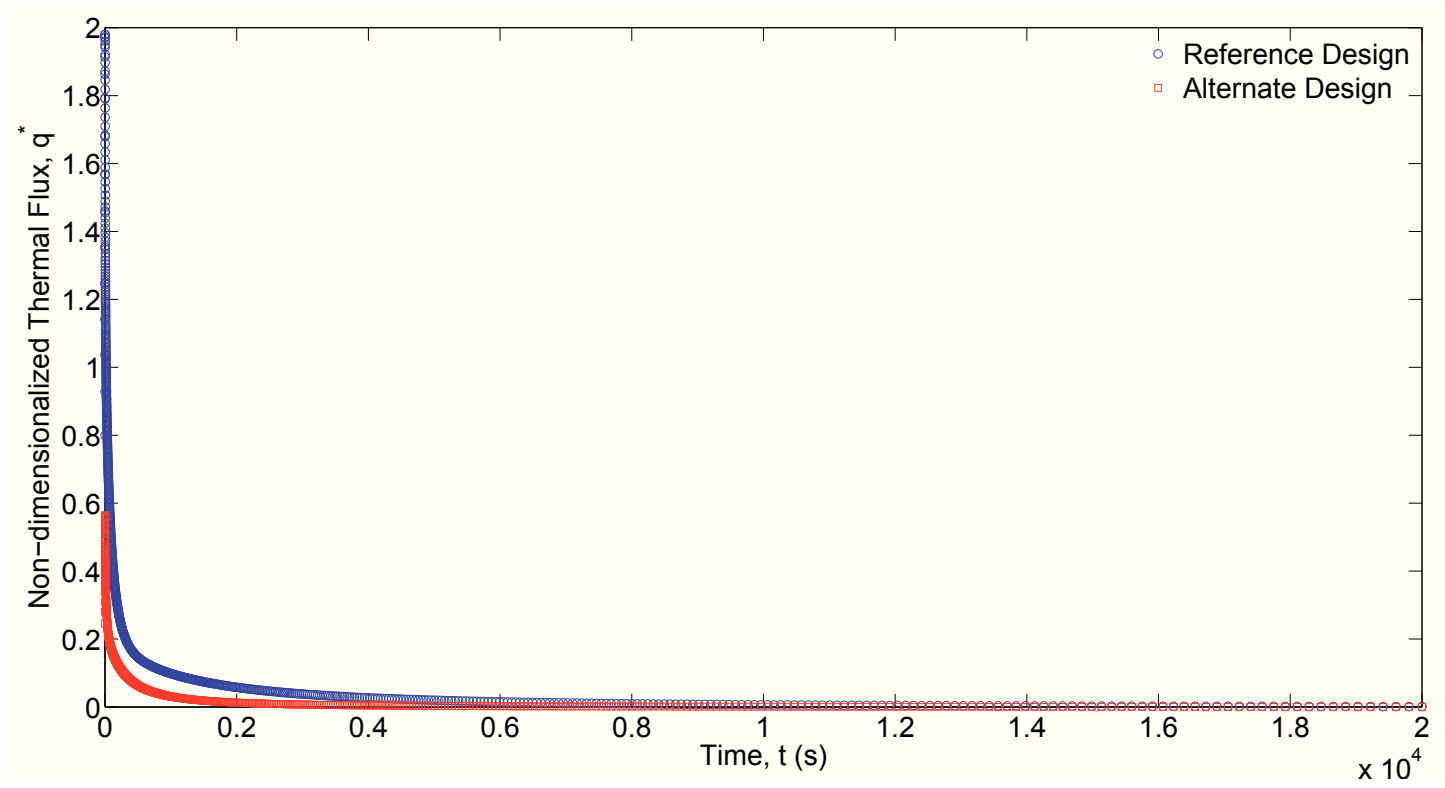

Figure 3.4: Time variation of the dimensionless LOCA thermal flux conducted by the inner liner. Quantities for both the reference and alternate designs are shown for the entire 20,000 s accident duration.

From Figure 3.4 it may be observed that the reference design operates at a higher efficiency relative to the alternate throughout the entire duration of the LOCA. It is clear that the thermal flux rejected by the reference design fuel channel decays to zero at a slower rate as it cools to a uniform temperature of $\mathrm{T}=\mathrm{T}_{\infty, m}=373 \mathrm{~K}$.

However, it was generally found that the alternate fuel channel configuration attained larger rates of heat rejection as a result of smaller water gaps. Although this circumstance is regarded favourably with respect to management of LOCA fuel temperatures, the inherent benefits come at a cost. That is, the thin water gaps that facilitate an enhanced thermal flux to the moderator during a LOCA also enable excessive heat loss during normal operation. With regards to the reference fuel channel configuration, the comparatively smaller accident thermal fluxes are offset by a lower rate of heat loss in normal operation, culminating in a more efficient design. 
Closer scrutiny is warranted for the dynamic behaviour immediately following the onset of the LOCA, as is illustrated in Figure 3.5:

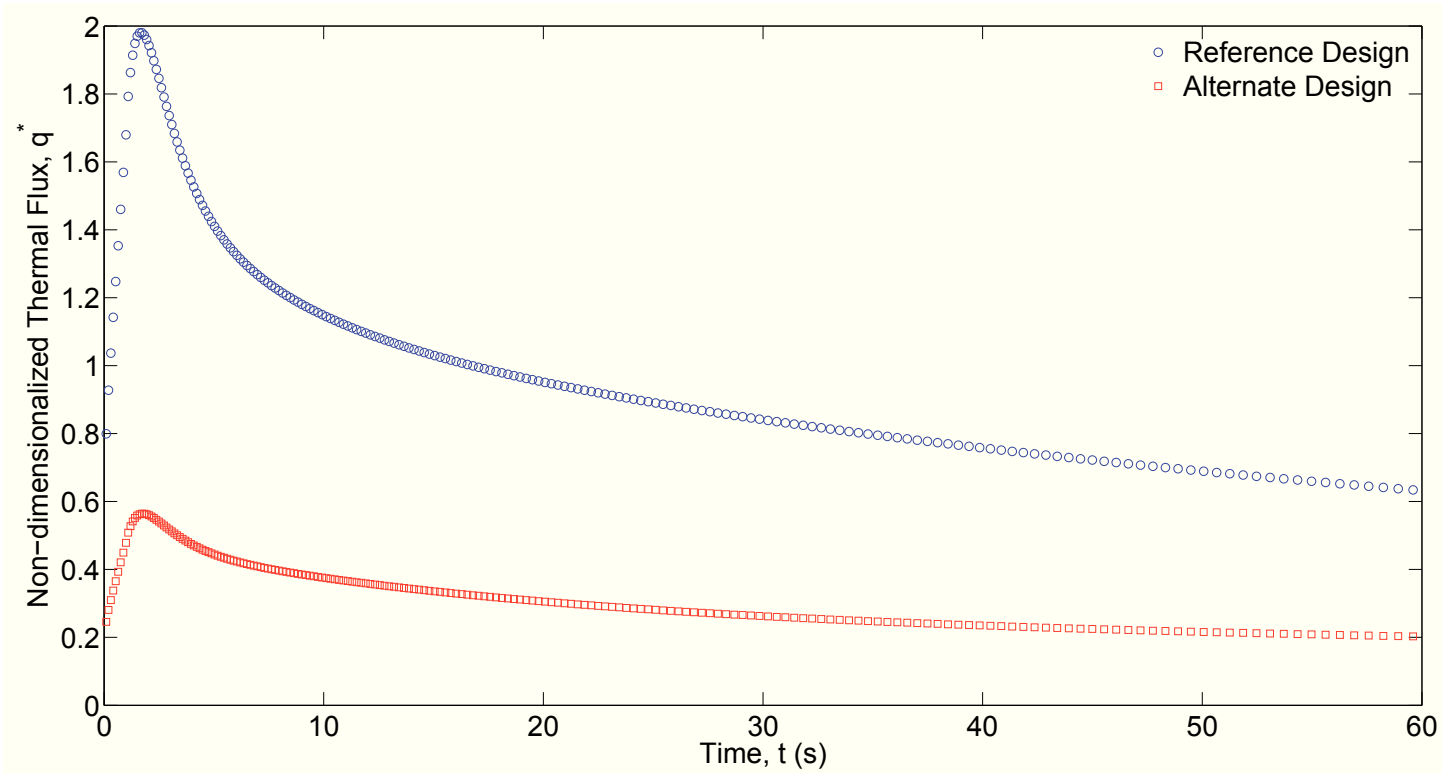

Figure 3.5: Time variation of the dimensionless LOCA thermal flux conducted by the inner liner for the first $60 \mathrm{~s}$.

It is evident from Figure 3.5 that both designs attain a peak $q^{*}$ after $1.8 \mathrm{~s}$ have transpired, with $q^{*}=1.98$ and 0.56 for the reference and alternate designs, respectively. This initial increase in efficiency is followed by a monotonic decrease towards $q^{*}=0$ as both fuel channel designs cool to a uniform steady-state temperature.

The $1.8 \mathrm{~s}$ interval noted previously is identical to that observed for the peak fuel cladding temperatures in Figure 3.2. This result would suggest that the LOCA heat rejection rate is closely related to the temperature of the fuel cladding. Equation (2.24) supports this conclusion, as the net-heat conducted by the inner liner depends on the temperature of every discrete surface comprising the fuel bundle/flow tube/inner liner enclosure. 
The peaks in $q^{*}$ discussed prior are preceded by rapid increases in the LOCA flux for both fuel channel designs. At $\mathrm{t}=0 \mathrm{~s}$, the instantaneous loss of convective cooling of the fuel instigates low rates of heat rejection. However, the resultant increase in cladding temperatures prompt enhanced radiative cooling of the fuel, culminating in the peaks at $\mathrm{t}=1.8 \mathrm{~s}$. A trend of decreasing $q^{*}$ ensues, whereby the fuel cladding begins to cool to $T_{\infty, m}=373 \mathrm{~K}$ with an accompanying decrease in radiosity from the bundle. 


\section{Chapter 4}

\section{Conclusions}

\subsection{Summary}

The objective of this investigation was to explore facets of the no-core-melt passive safety feature that had thus far not been addressed by past research. In particular, this goal was achieved utilizing the following techniques:

- The thermal and stress simulations were coupled together in order to exchange data at each time-step. This method enabled calculation of the fuel channel component deformations under combined thermal and mechanical loads, as well as the ensuing changes in heat transfer across the contracting/expanding water gaps.

- Radiation heat exchange was modelled between the inner liner, 64-pin fuel bundle, and flow tube for the LOCA case. Although this phenomenon had been simulated in past research, a survey of the literature revealed that the majority of these analyses had used dated pin configurations. 
- In addition to the reference fuel channel design described in chapter $\mathbf{2}$ Methods, an alternate design consisting of smaller water gaps was also simulated. This approach granted insight into the relationship between the fuel channel dimensions and the consequent heat transfer characteristics.

In conjunction with the novel techniques enumerated above, the VrSuite FEM software was used to simulate the reference and alternate fuel channel designs operating in normal/LOCA scenarios. Particularly close attention was paid to the maximum temperature attained in the fuel cladding as the no-core-melt safety feature stipulates sub-melting accident temperatures in this component (i.e, $<1,450{ }^{\circ} \mathrm{C}$ for stainless steel). To this end, it was observed that both fuel channel configurations achieved safe peak cladding temperatures of $1,120^{\circ} \mathrm{C}$.

The nearly identical cladding temperatures yielded by the two fuel channel designs necessitated another metric to identify the more efficient configuration. For this purpose, a ratio of the LOCA and normal operation thermal fluxes was introduced as an analog to the fuel channel efficiency, with better performing designs tending to minimize heat losses in normal operation while maximizing thermal flux from the fuel bundle during a LOCA. In this way, it was determined that the reference design operated at a higher efficiency throughout the duration of the LOCA, with its peak efficiency of $q^{*}=1.98$ comparing favourably with the $q^{*}=0.56$ peak attained by the alternate design.

However, the matter was further convoluted when the fuel cladding temperatures were monitored for the entire 20,000 s accident duration. In particular, it was observed that the alternate design garnered a more rapid cooling of the fuel to its steady-state temperature (that is, the ambient temperature of the moderator). This trait may be considered to be highly beneficial, as it implies that the fuel cladding will spend less time at near-melting temperatures. 
When the two prior observations are taken in tandem, it is apparent that further research is required to ascertain one metric that encapsulates all of the pertinent merits of such fuel channel designs. For instance, a weighted average of the thermal flux ratio and cladding cooling rate discussed above could serve as a useful means for future optimization of the fuel channel dimensions.

\subsection{Future Work}

Although the observations presented in this thesis have facilitated new insights into the no-core-melt concept, it is plausible that some of the simplifying assumptions and other limitations described earlier have induced a degree of inaccuracy in the results. To this end, future research should aim to expand upon the scope of this thesis and several potential enhancements have been enumerated below.

Highest priority should be given to optimization of the fuel channel dimensions. As was mentioned in Section 3.1 Maximum Cladding Surface Temperature, this process would first require definition of a valid objective function. In turn, it should be possible to identify a fuel channel design that attains a state of no-core-melt in the most efficient fashion. For further information concerning the optimization procedure, the reader may refer to Appendix F: Fuel Channel Design Optimization and Appendix G: VrSuite Verification - Optimization Tool.

Heat transfer through the three water gaps is governed by four mechanisms, as per Equation (2.6). However, the VrSuite FEM software currently models only conductive heat transfer during normal operation and LOCA scenarios. Due to the high fuel temperatures accompanying a LOCA, the fuel channel components may be subjected to large thermal strains resulting in elastic deformations. If the magnitudes of these deformations are sufficiently large, two or more of the components may come into physical contact; a highly desirable consequence as heat will transfer through the 
enmeshing asperities, thus increasing the rate of heat rejection to the moderator in accident conditions. The thermal conductance due to this physical contact between parts may be approximated by [11][12]:

$$
\Omega_{A s p}=\beta(\sigma \cdot n)^{\alpha}
$$

Compilation of experimental data would be required in order to estimate the quantities of $\alpha$ and $\beta$. In addition, further programming would be required to export the stress field from the stress solver to the thermal solver; a treatment similar to that of the displacement field described in 2.7.1 Solver Coupling. Implementation of this feature would supersede the "maximum conductance" technique illustrated earlier in this document as it models the physics of thermal contact in a more realistic manner.

Another prominent limitation inherent in this analysis is the use of DittusBoelter's correlation for estimation of many of the heat transfer coefficients in normal operation. Although this correlation is commonly used for its simplicity, other experimentally derived relationships exist with greater accuracy [8][21]. To achieve more rigorous results, advection/diffusion and fluid flow solvers could be coupled via CFD software to more precisely model complicated heat exchange between the upwardflowing coolant and 64-pin fuel bundle.

In light of the high cladding temperatures resulting from a LOCA, it was imperative that thermal radiation heat transfer be accurately modelled in the VrSuite FEM software. However, large cladding temperatures on the order of 1,140 K were observed during normal operation as well. Consequently, future analyses should simulate thermal radiation in normal operation too; a measure that was not incorporated in this thesis due to the difficulty associated with modelling participating media (i.e, the supercritical water coolant). In spite of this aforementioned complication, numerical techniques exist for estimating interactions with these media [24], and the appropriate 
software may grant valuable insight into thermal radiation heat exchange in normal operation.

In a similar vein, all LOCA simulations described here assumed diffuse-grey surfaces with temperature-independent thermo-optical properties. These steps were taken to circumvent a multitude of complexities, but in reality the absorbtivity, reflectivity, and emissivity of a surface vary with the angles of incidence and emission, radiation wavelength, and temperature [24]. Future no-core-melt research may endeavour to implement some or all of these features in order to more accurately approximate thermal radiation heat exchange in a typical fuel channel.

The analyses detailed in this thesis assumed a constant ambient moderator temperature of $100{ }^{\circ} \mathrm{C}$ for the entire LOCA duration. In reality however, heat rejection from the pressure tube during an accident may cause localized boiling of the heavy water in the vicinity of the pressure tube/moderator interface. This phenomenon was not simulated in the FEM software given its complexity. However, it is conceivable that a boiling model may have significant implications on the numerically computed cladding temperatures during the LOCA.

Given the complicated nature of heat transfer in the SCWR fuel channels, the governing equations are analytically intractable. Thus, a series of simple test problems were necessary to verify the FEM software used in the analyses. Alternatively, the results presented here may be validated against the numerical simulations documented in the literature. However, this technique would not grant any sort of insight into how accurately the model approximates the governing physics. Therefore, the only way to unequivocally measure the accuracy of the results presented in this thesis would be through experimentation; likely a distant prospect considering the infancy of no-core-melt research. 


\section{References}

[1] L.K.H. Leung, M. Yetisir, W. Diamond, D. Martin, J. Pencer, B. Hyland, H. Hamilton, D. Guzonas, and R. Duffey. A next generation heavy water nuclear reactor with supercritical water as coolant. In International Conference Future of HWR's, Ottawa, Ontario, Canada, 2-5 October 2011.

[2] M. Yetisir, M. Gaudet, D. Rhodes, H. Hamilton, and J. Pencer. Reactor core and passive safety systems descriptions of a next generation pressure tube reactor mechanical aspects. In The 19th Pacific Basin Nuclear Conference (PBNC 2014), Vancouver, British Columbia, Canada, 24-28 August 2014.

[3] J. Licht. Moderator cooling requirements for the Canadian SCWR. In The $6^{\text {th }}$ International Symposium on Supercritical Water-Cooled Reactors (ISSCWR-6), Shenzhen, Guangdong, China, 3-7 March 2013.

[4] P. Wu, J. Shan, J. Gou, Bin Zhang, and Bo Zhang. Preliminary no core melt assessment for Canadian SCWR with modified SCTRAN. In 2014 Canada-China Conference on Advanced Reactor Development (CCCARD-2014), Niagara Falls, Ontario, Canada, 27-30 April 2014.

[5] J. Licht and R. Xu. Preliminary no-core melt assessment for the high efficiency channel preconceptual design. In The $3^{\text {rd }}$ China-Canada Joint Workshop on Supercritical Water-Cooled Reactors, Xi'an, China, 18-20 April 2012.

[6] J. Shan, Y. Jiang, and L.K.H. Leung. Subchannel and radiation heat transfer analysis of 54-element CANDU-SCWR bundle. In The $5^{\text {th }}$ International Symposium on Supercritical Water-Cooled Reactors (ISSCWR-5), Vancouver, British Columbia, Canada, 13-16 March 2011.

[7] A. Vasic and H.F. Khartabil. Passive cooling of the CANDU SCWR fuel at LOCA/LOECC conditions. In Proceedings of GLOBAL 2005, Tsukuba, Japan, 9-13 October 2005. 
[8] Y. A. Çengel. Heat and Mass Transfer - A Practical Approach. McGraw-Hill Education, $3^{\text {rd }}$ edition, 2007.

[9] J. Goldak, M. Yetisir, and R. Pistor. The role of computational weld mechanics in the weld repair of Canada's NRU nuclear reactor. In Proceedings of the ASME 2013 Pressure Vessels 63 Piping Division Conference (PVP2013-97948), Paris, France, 14-18 July 2013.

[10] D. Radford. Mechanical and constitutive behaviour of Zr-2.5Nb pressure tube material at high rates of tensile strain. Doctor of Philosophy in Mechanical Engineering, Carleton University, Ottawa, ON, Canada, 2000.

[11] J. Goldak, V. Aldea, J. Zhou, S. Wang, M. Mocanita, D. Downey, and B. Wang. Coupled thermal stress analysis in die casting: A contact problem. In First M.I.T. Conference on Computational Fluid and Solid Mechanics, Cambridge, Massachusetts, USA, 12-14 June 2001.

[12] S. Song, M. M. Yovanovich, and F. O. Goodman. Thermal gap conductance of conforming surfaces in contact. Journal of Heat Transfer, 115:533-540, August 1993.

[13] National Institute of Standards and Technology. Thermophysical properties of fluid systems. Online Document. Retrieved from http://webbook.nist.gove/chemistry/fluid/.

[14] The International Association for the Properties of Water and Steam. Zittau's fluid property calculator. Online Document. Retrieved from http://thermodynamik.hs-zigr.de/fpc/index.php.

[15] G. Schmidt, M. Yetisir, and J. Goldak. Preliminary numerical modelling of no-core-melt in the Generation IV Canadian SCWR. In 2014 Canada-China Conference on Advanced Reactor Development (CCCARD-2014), Niagara Falls, Ontario, Canada, 27-30 April 2014.

[16] International Atomic Energy Agency. Thermophysical properties database of materials for light water reactors and heavy water reactors. Technical report, June 2006. Final report of a coordinated research project.

[17] K.W. Schlichting, N.P. Padture, and P.G. Klemens. Thermal conductivity of dense and porous yttria-stabilized zirconia. Journal of Materials Science, 36:3003-3010, 2001. 
[18] C. Cozzo, D. Staicu, J. Somers, A. Fernandez, and R.J.M. Konings. Thermal diffusivity and conductivity of thorium-plutonium mixed oxides. Journal of Nuclear Materials, 416:135-141, September 2011.

[19] K. Bakker, E.H.P. Cordfunke, R.J.M. Konings, and R.P.C. Schram. Critical evaluation of the thermal properties of $\mathrm{ThO}_{2}$ and $\mathrm{Th}_{1-y} \mathrm{U}_{y} \mathrm{O}_{2}$ and a survey of the literature data on $\mathrm{Th}_{1-y} \mathrm{Pu}_{y} \mathrm{O}_{2}$. Journal of Nuclear Materials, 250:1-12, July 1997.

[20] M. Nimrouzi. A methodology for optimal design of the Canadian SCWR reactor core. M.A. Sc. - Mechanical Engieering, Carleton University, Ottawa, ON, Canada, 2014.

[21] Frank P. Incropera and D. DeWitt. Fundamentals of Heat and Mass Transfer. John Wiley and Sons, Inc., Hoboken, NJ, United States of America, $4^{\text {th }}$ edition, 2000.

[22] T.F. Irvine and M.R. Duignan. Isobaric thermal expansion coefficients for water over large temperature and pressure ranges. International Communications in Heat and Mass Transfer, 12:465-478, 1985.

[23] J. Kestin, J.V. Sengers, B. Kamgar-Parsi, and J.M.H. Levelt. Thermophysical properties of fluid $\mathrm{D}_{2} \mathrm{O}$. Journal of Physical Chemistry, 13:601-609, 1984.

[24] J. R. Howell, R. Siegel, and M. P. Menguç. Thermal Radiation Heat Transfer. CRC Press, Taylor and Francis Group, Boca Raton, FL, United States of America, $5^{\text {th }}$ edition, 2011.

[25] Maya Heat Transfer Technologies Ltd. NX 8.5 Thermal Solver TMG Reference Manual, 2012.

[26] M. F. Cohen and J. R. Wallace. Radiosity and Realistic Image Synthesis. Academic Press Professional, Cambridge, MA, United States of America, 1993.

[27] J. Goldak. Volumetric thermal stress. Technical paper, May, 2014.

[28] J. Sacks, W. J. Welch, T. J. Mitchell, and H. P. Wynn. Design and analysis of computer experiments. Statistical Science, 4:409-423, November 1989.

[29] C. E. Rasmussen and C. K. I. Williams. Gaussian Processes for Machine Learning. The MIT Press, Cambridge, MA, United States of America, 2006.

[30] R.C. Hibbeler. Mechanics of Materials. Pearson Education South Asia Pte. Ltd., Singapore, $8^{\text {th }}$ edition, 2011. 


\section{Appendix A}

\section{Time-Step Dependency Study}

Section 2.7.2 Simulation Parameters addressed the application of an exponential time-stepping scheme to the LOCA analyses. The large temperature changes in the initial seconds of the accident required small time-steps to accurately model the transient. In contrast, the requirements in the latter stages were less stringent as the solution approached steady-state.

In light of these large temperature variations at the onset of the LOCA, it was important to ensure that the initial time-steps were sufficiently small to accurately capture such behaviour. For this purpose, the exponential time-stepping scheme (with $\Delta t^{1}=0.1 \mathrm{~s}$ and $\left.\mathrm{a}=1.01\right)$ studied in this thesis was compared with three variants by plotting the respective cladding temperatures for the first two seconds of the accident: 


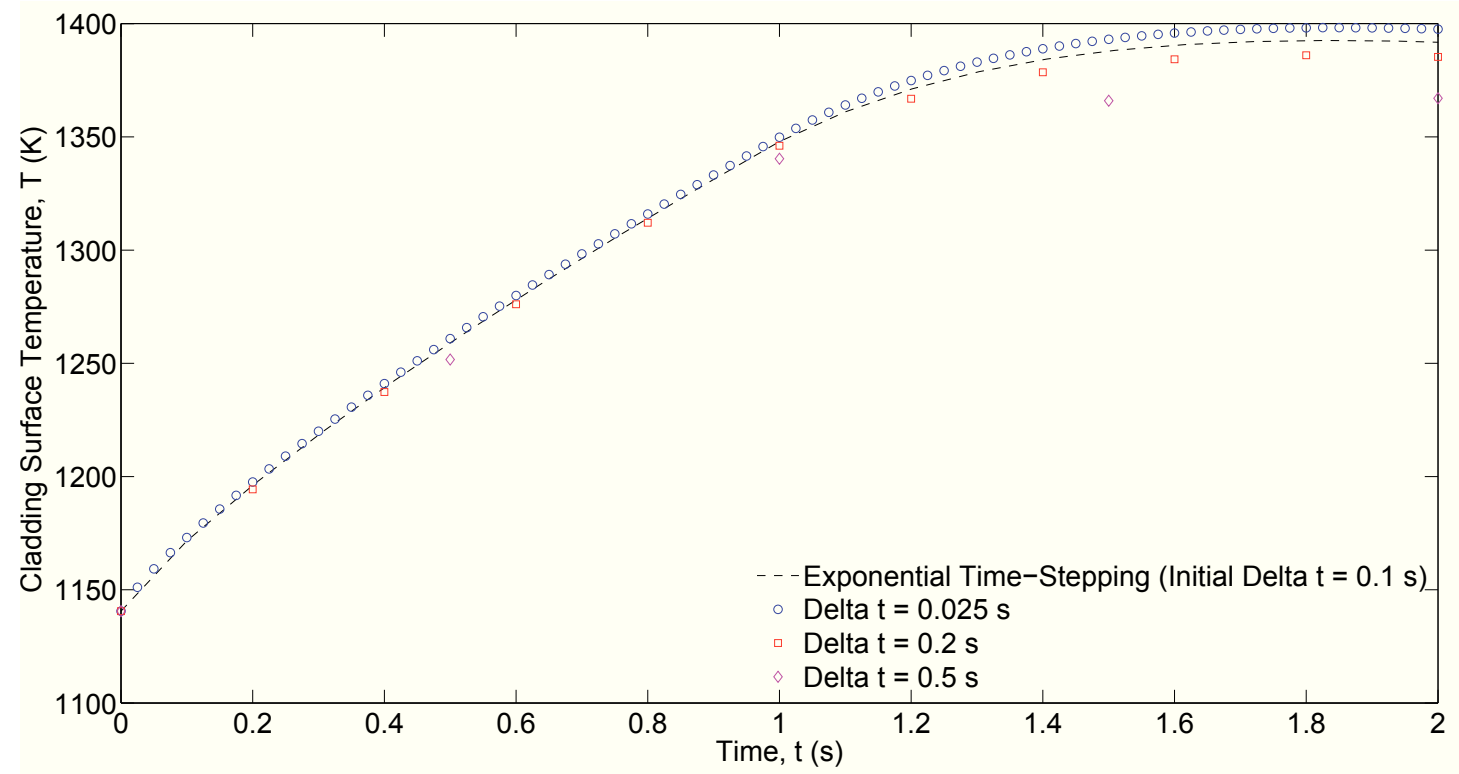

Figure A.1: Reference design cladding temperatures in the first $2 \mathrm{~s}$ following the LOCA.

Figure A.1 would suggest that that the cladding temperatures yielded by the various time-step sizes deviate most significantly at the two second mark. These discrepancies have been summarized in Table A.1 below:

Table A.1: Reference design cladding temperatures at $\mathrm{t}=2 \mathrm{~s}$ for time-steps sizes of $0.025 \mathrm{~s}, 0.1 \mathrm{~s}, 0.2 \mathrm{~s}$, and $0.5 \mathrm{~s} . \Delta t=0.1 \mathrm{~s}$ used an exponential time-stepping scheme, whereas the remainder used constant time-stepping.

\begin{tabular}{|c|c|c|}
\hline Time-Step Size & Cladding Temperature & Percent Difference \\
\hline$\Delta \mathrm{t}=0.5 \mathrm{~s}$ & $1,367 \mathrm{~K}$ & $2.18 \%$ \\
\hline$\Delta \mathrm{t}=0.2 \mathrm{~s}$ & $1,385 \mathrm{~K}$ & $0.88 \%$ \\
\hline$\Delta \mathrm{t}=0.1 \mathrm{~s}$ (Exp.) & $1,391 \mathrm{~K}$ & $0.44 \%$ \\
\hline$\Delta \mathrm{t}=0.025 \mathrm{~s}$ & $1,398 \mathrm{~K}$ & $\mathrm{~N} / \mathrm{A}$ \\
\hline
\end{tabular}

Where the percent differences seen above were computed as follows:

$$
\% \operatorname{Diff}=\frac{\left|T_{\Delta t_{i}}-T_{\Delta t=0.025 \mathrm{~s}}\right|}{T_{\Delta t=0.025 \mathrm{~s}}} \cdot 100 \%
$$


The comparatively small difference in cladding temperatures between the $\Delta t=0.1 \mathrm{~s}$ and $0.025 \mathrm{~s}$ cases would suggest that further reductions in time-step size will instigate only marginal effects. Therefore, it may be concluded that the LOCA exponential discretization scheme described earlier nearly attained a solution independent of timestep size. 


\section{Appendix B}

\section{VrSuite Verification - Thermal Solver}

\section{B.1 Numerical Solution}

Verification of VrSuite's thermal solver was performed on a $0.5 \mathrm{~mm}$ thick quadrant of the reference fuel channel design, as shown in Figure B.1 below:

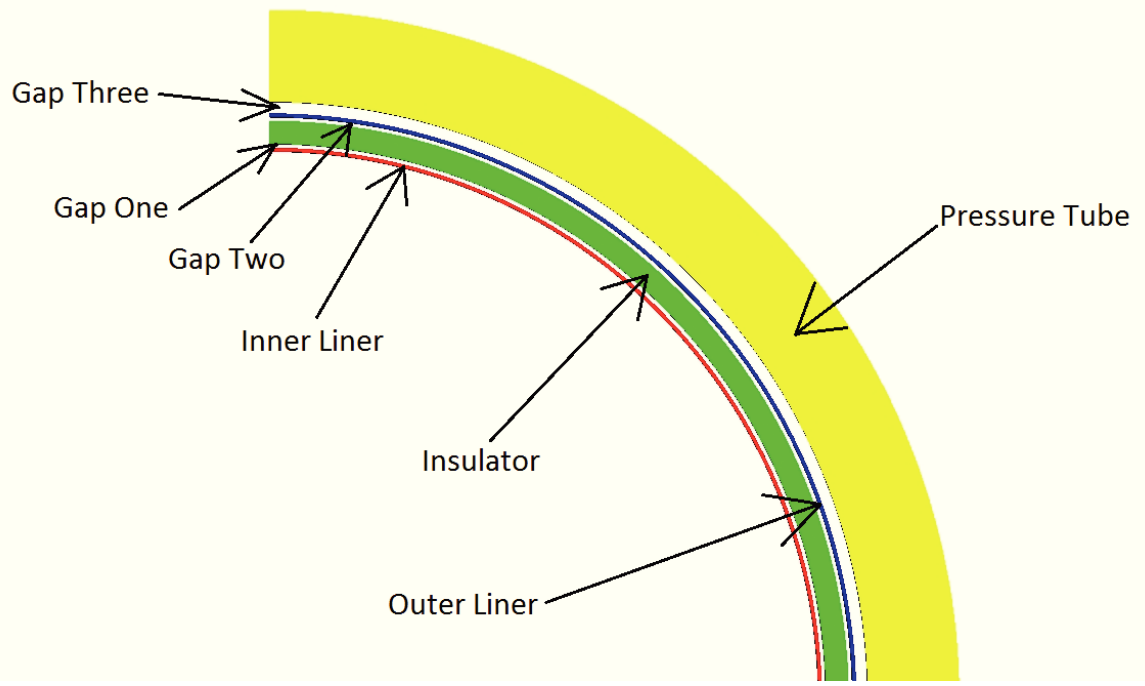

Figure B.1: Thin fuel channel quadrant used to verify VrSuite's thermal solver.

Notably absent from the geometry illustrated in Figure B.1 is the 64-pin fuel bundle. For normal operation and accident conditions, heat flux from the fuel bundle to the inner liner was approximated by convection and radiation conductances, respectively. 
Specifically, $h_{C o n v}$ was estimated via Dittus and Boelter's correlation and $\Omega_{R a d}$ was computed using the following relationship [11]:

$$
\Omega_{R a d}=S \epsilon\left(T_{\infty, c}^{2}+T_{l}^{2}\right)\left(T_{\infty, c}+T_{l}\right)
$$

All computed thermal conductances and their corresponding ambient temperatures have been summarized in Table B.1:

Table B.1: Thermal conductances and ambient temperatures prescribed at the inner surface of the inner liner.

\begin{tabular}{|c|c|c|c|}
\hline & $\begin{array}{c}\text { Normal Op. } \\
\text { (Bottom of Channel) }\end{array}$ & $\begin{array}{c}\text { Normal Op. } \\
\text { (Top of Channel) }\end{array}$ & LOCA \\
\hline Thermal Conductance & $2,005 \mathrm{~W} / \mathrm{m}^{2} \cdot \mathrm{K}$ & $2,005 \mathrm{~W} / \mathrm{m}^{2} \cdot \mathrm{K}$ & $859 \mathrm{~W} / \mathrm{m}^{2} \cdot \mathrm{K}$ \\
\hline Ambient Temperature & $350^{\circ} \mathrm{C}$ & $625^{\circ} \mathrm{C}$ & $1,450^{\circ} \mathrm{C}$ \\
\hline
\end{tabular}

On the moderator-side, the pressure tube surface temperatures were used in conjunction with the curve fits displayed in Figure 2.7 to estimate the convection conductances.

The geometry and boundary conditions detailed above were simulated in VrSuite for durations of $400 \mathrm{~s}$; sufficiently long to ensure that all coupled thermal/stress solutions had attained steady-state.

\section{B.2 Analytical Solution}

Each of the components and water gaps described previously were modelled analytically as a series of thermal resistors, as depicted in Figure B.2 on the following page: 


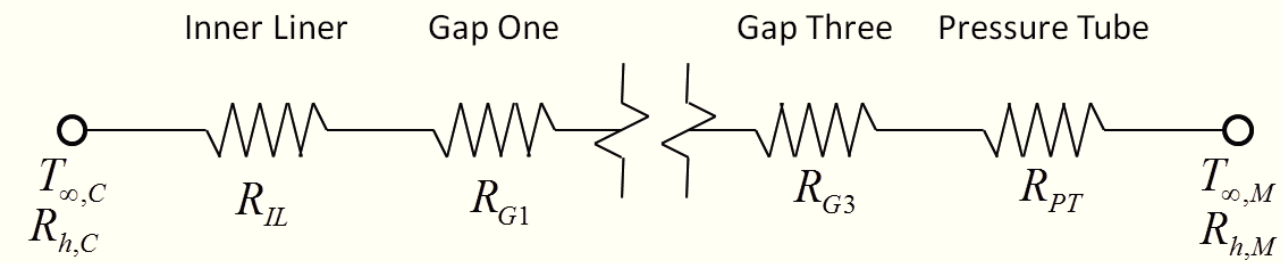

Coolant

Moderator

Figure B.2: Schematic illustrating the fuel channel components and water gaps modelled as a series of thermal resistors.

If, for example, the thermal resistances across the coolant-side thermal boundary layer and inner liner are considered, the magnitudes of these thermal resistances were evaluated as follows [8]:

$$
R_{h, c}=\frac{1}{2 \pi r_{i, I L} L h_{C o n v}} \text { and } R_{I L}=\frac{1}{2 \pi L k_{I L}} \ln \left(\frac{r_{o, I L}}{r_{i, I L}}\right)
$$

Where the thermal conductivities were evaluated at the steady-state average component/gap temperatures computed by VrSuite. Similarly, the deformed component/gap radii, $r$, were taken from VrSuite's stress solver after attaining steady-state. Adding all of these thermal resistances in series facilitated computation of the total heat transfer rate from the coolant to moderator, as illustrated below:

$$
Q_{T o t}=\left(T_{\infty, c}-T_{\infty, m}\right)\left[\sum_{i=1}^{N} R_{i}\right]^{-1}
$$

Where the subscript $i$ seen above is an identifier indicating a component or water gap (i.e, $i=1$ would indicate the inner liner thermal boundary layer, $i=2$ the inner liner, $i=3$ the first water gap,..., and $i=N$ the pressure tube thermal boundary layer). In turn, the analytically derived temperature drops through the fuel channel may be predicted as follows:

$$
\Delta T_{i}=Q_{T o t} R_{i}
$$


Which may subsequently be used to generate a radial temperature distribution via linear interpolation.

\section{B.3 Results}

The numerically and analytically derived radial temperature distributions have been plotted in Figure B.3 below for normal operation (bottom and top of fuel channel) and LOCA scenarios:
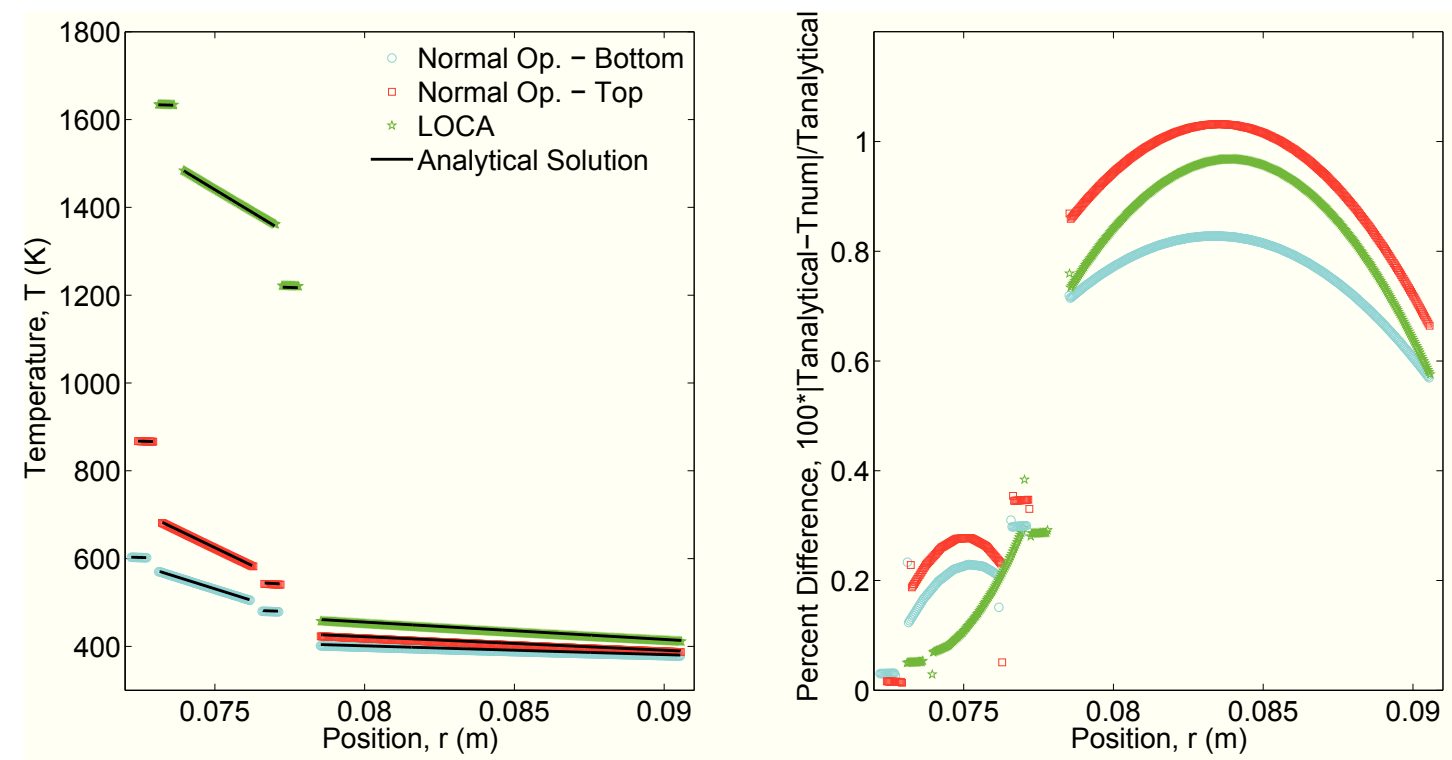

Figure B.3: Analytically and numerically derived radial temperature distributions (left). Percent differences as a function of position have also been plotted (right).

From Figure B.3, a global maximum percent difference of approximately $1.03 \%$ may be observed between the analytical and numerical results (for the normal operation case at the top of the fuel channel). This outcome suggested that VrSuite's FEM thermal solver was yielding sufficiently accurate quantities for the simple test case; a conclusion that may plausibly be extended to the more complicated fuel channel model described in the body of this thesis as well. 


\section{Appendix C}

\section{VrSuite Verification - Stress Solver}

\section{C.1 Numerical Solution}

In order to verify VrSuite's FEM stress solver, a single 8-node volume element was simulated as shown in Figure C.1:

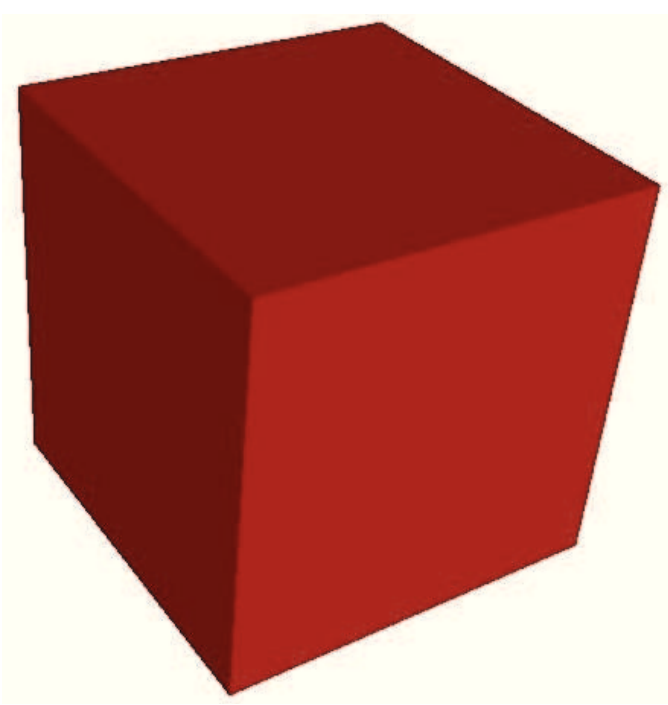

Figure C.1: 8-node volume element simulated in VrSuite with dimensions of 0.5 $\mathrm{mm} \times 0.5 \mathrm{~mm} \times 0.5 \mathrm{~mm}$.

A constant linear coefficient of thermal expansion of $\lambda=1.78 \mathrm{e}^{-5} \mathrm{~K}^{-1}$ was prescribed as an analog to the stainless steel inner liner at a temperature of $\mathrm{T}=1,650 \mathrm{~K}$ 
(the approximate steady-state temperature during LOCA, as seen in Figure B.3). Accordingly, a uniform temperature of $\mathrm{T}=1,650 \mathrm{~K}$ was applied to three faces of the volume element depicted in Figure C.1, with the remaining three faces being constrained in their respective spatial dimensions in order to restrain any rigid body motion. This measure permitted the three unconstrained faces of the element to deform under the thermal load.

\section{C.2 Analytical Solution}

When the volume element is subjected to an incremental temperature change from its initial state, the thermal strain in any of the three dimensions (for an isotropic material undergoing elastic strain, as is being considered here) may be predicted analytically via the following relationship [27]:

$$
\lambda(T)\left(T-T_{0}\right)=\frac{L(T)-L\left(T_{0}\right)}{L\left(T_{0}\right)}=\theta(T)
$$

Hence, the sought-after analytical thermal expansion, $\Delta L_{A}$, may be defined as follows:

$$
\Delta L_{A}=L\left(T_{0}\right) \lambda(T)\left(T-T_{0}\right)
$$

\section{C.3 Results}

Assuming an initial temperature of $\mathrm{T}_{0}=300 \mathrm{~K}$ for both numerical and analytical solutions, an applied temperature of $\mathrm{T}=1,650 \mathrm{~K}$ instigated thermal deformations of $\Delta L_{N}=1.2083 e^{-5} \mathrm{~m}$ and $\Delta L_{A}=1.2083 \mathrm{e}^{-5} \mathrm{~m}$, respectively. Given that these results are identical within the four given decimal places, it is reasonable to conjecture that the VrSuite thermal deformations calculated for the fuel channel model also obey the governing physics well. 


\section{Appendix D}

\section{VrSuite Verification - Radiation Solver}

\section{D.1 Numerical Solution}

Verification of VrSuite's radiation solver was conducted on two 8-node volume elements of dimensions $10 \mathrm{~cm} \mathrm{x} 10 \mathrm{~cm}$ x $10 \mathrm{~cm}$. A screencapture of this geometry with all relevant boundary conditions is depicted below in Figure D.1:

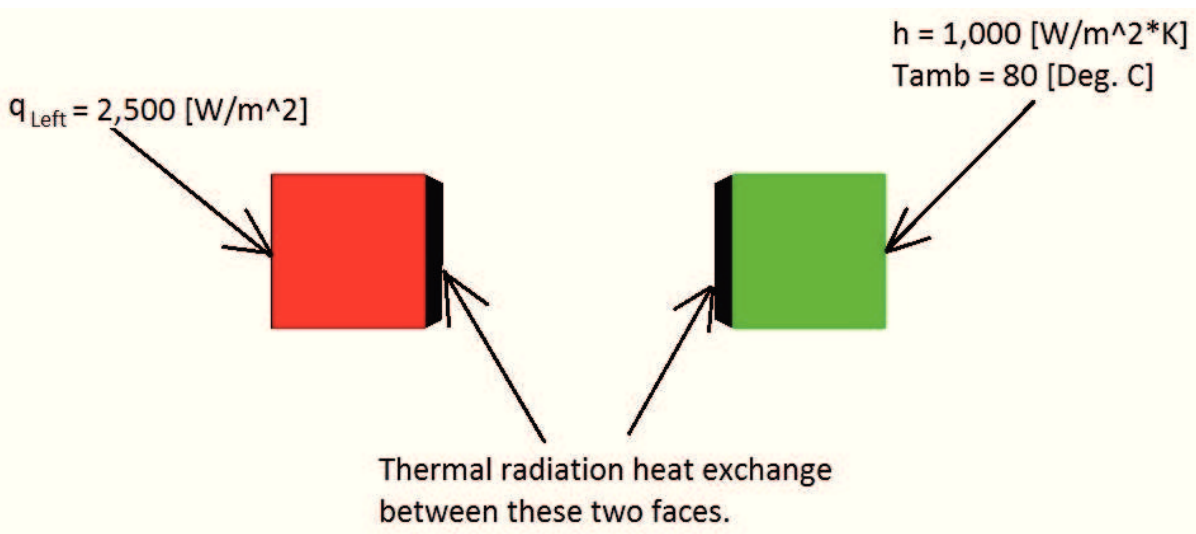

Figure D.1: 8-node volume elements simulated in the VrSuite radiation test case. The two surfaces indicated in the figure were thermally coupled via radiation heat exchange, with constant flux and convection boundary conditions applied to the left-most and right-most surfaces, respectively. The remaining surfaces were thermally insulated.

It is prudent to note that the spacing between volume elements was selected arbitrarily and considered to be immaterial to the analysis. This is because the view factor was 
specified via user input and not calculated from the geometry.

In conjunction with a constant thermal conductivity of $\mathrm{k}=1.8 \mathrm{~W} / \mathrm{m} \cdot \mathrm{K}$, three test cases were simulated with $[\epsilon=0.3, \mathrm{~F}=0.5],[\epsilon=0.8, \mathrm{~F}=0.9]$ and $[\epsilon=1, \mathrm{~F}=1]$. Note that in the three aforementioned test cases the emissivities were applied to both of the surfaces participating in thermal radiation heat exchange. All simulations were permitted to run to steady-state with durations and time-steps of 500,000 s and 100 $\mathrm{s}$, respectively.

\section{D.2 Analytical Solution}

Equations (2.1) and (2.24) dictate the time-evolution of heat flow through/between the left and right volume elements. At steady-state in particular, the thermal flux applied to the left-most surface is conducted through the left volume followed by radiation across the interface. A fraction of this radiant energy is emitted without striking the opposing surface and is ultimately absorbed by the surroundings:

$$
q_{\text {Surr }}=(1-F) q_{\text {Left }}
$$

The remaining radiant energy is incident upon the opposite surface, however a portion is reflected without being absorbed by the right volume:

$$
q_{\text {Ref }}=\gamma\left(q_{\text {Left }}-q_{\text {Surr }}\right)=(1-\epsilon) F q_{\text {Left }}
$$

Thus, the steady-state thermal flux absorbed and conducted through the right cube may be expressed as follows:

$$
q_{\text {Right }, A}=q_{\text {Left }}-q_{\text {Surr }}-q_{\text {Ref }}=\epsilon F q_{\text {Left }}
$$

Where the subscript $A$ denotes the flux calculated via analytical means. 


\section{D.3 Results}

The steady-state temperature distributions (right-most element only) gleaned from VrSuite have been plotted in Figure D.2:

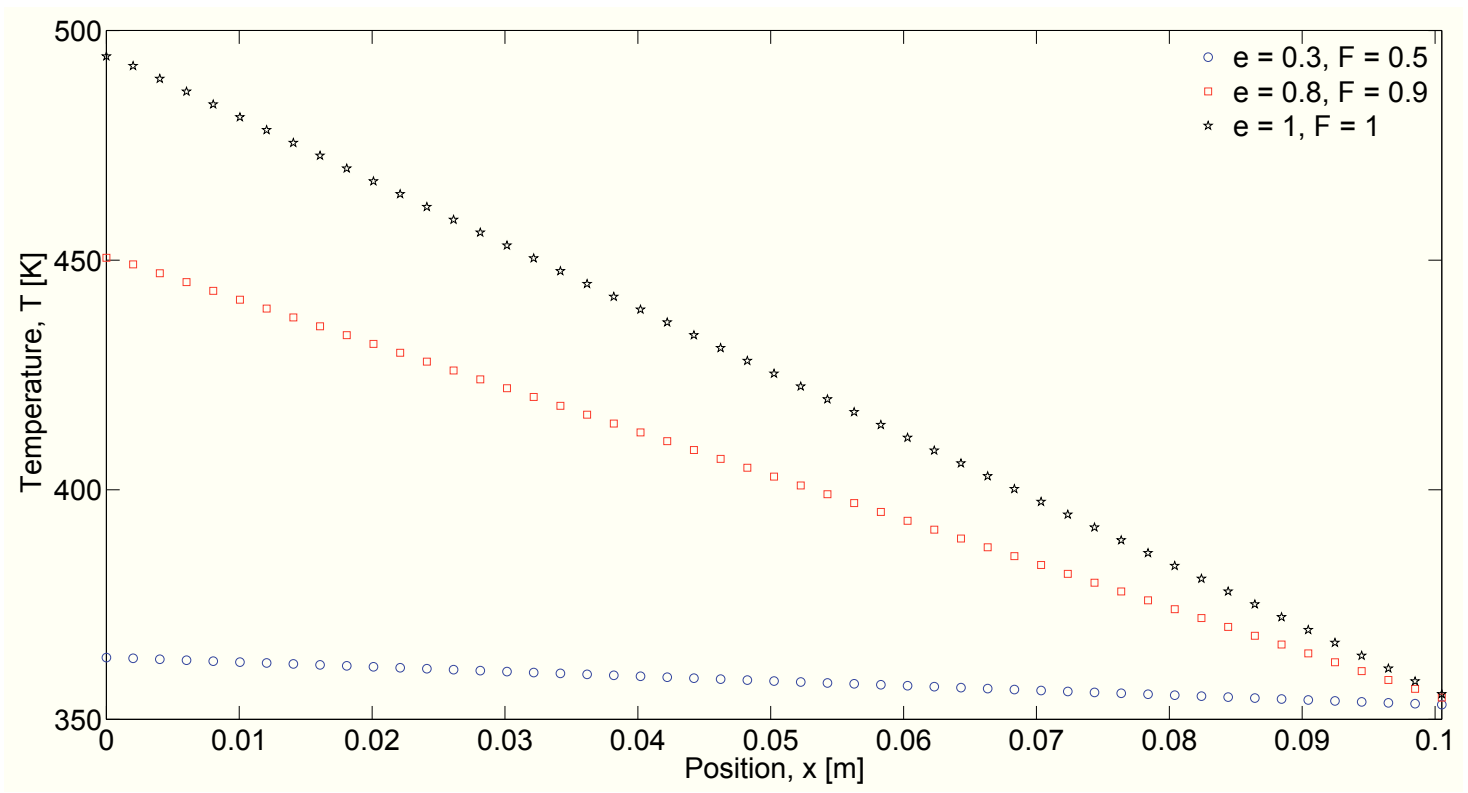

Figure D.2: Numerically derived temperature distributions through the right volume element for the three test cases.

The numerically derived temperature distributions appearing in Figure D.2 permitted computation of the heat flow through the right volume element via the following relationship:

$$
q_{R i g h t, N}=k \frac{\Delta T_{R}}{L_{R}}
$$

The resulting numerically and analytically determined thermal fluxes conducted through the right cube have been summarized in Table D.1 on the next page: 
Table D.1: Steady-state thermal fluxes through the right volume element computed by numerical and analytical methods.

\begin{tabular}{|c|c|c|c|}
\cline { 2 - 4 } \multicolumn{1}{c|}{} & $\begin{array}{c}q_{\text {Right }, N} \\
{\left[W / m^{2}\right]}\end{array}$ & $\begin{array}{c}q_{\text {Right }, A} \\
{\left[W / m^{2}\right]}\end{array}$ & $\begin{array}{c}\text { Percent } \\
\text { Difference }\end{array}$ \\
\hline$\epsilon=0.3, F=0.5$ & 184.72 & 375.00 & 50.74 \\
\hline$\epsilon=0.8, F=0.9$ & $1,724.29$ & $1,800.00$ & 4.21 \\
\hline$\epsilon=1, F=1$ & $2,499.93$ & $2,500.00$ & 0.0028 \\
\hline
\end{tabular}

It is apparent from the quantities presented above that smaller view factors and emissivities yield larger discrepancies between numerically and analytically measured fluxes. This phenomenon is likely a product of the nature of the net radiation method and its implementation in the VrSuite software. In particular, one may recall from section 2.6.2 Thermal Analysis - LOCA that Equation (2.24) requires a system of $M$ equations for closure of a heat exchange problem, where $M$ is the number of surfaces comprising an enclosure. However, the test cases utilizing $\mathrm{F}=0.5$ and 0.9 do not constitute an enclosure, with a fraction $(1-F)$ of the steady-state energy emitted by the left volume being radiated to the surroundings. As the VrSuite software does not consider heat exchange with the surroundings, it is conceivable that numerical solution of Equation (2.24) will precipitate inaccuracies inversely proportional with the magnitude of the view factor.

The preceding discussion also has important implications for the fuel channel model presented in this thesis. Specifically, it was assumed in section 2.6.2 Thermal Analysis - LOCA that the inner liner completely enclosed the flow tube and fuel bundle as the length of the liner far exceeds its radius. This distinction implied that thermal radiation emitted/reflected by the various surfaces and passing through the bottom and top openings of the assembly was negligible, such that: 


$$
\sum_{j=1}^{N} F_{i-j}=1
$$

Where the subscript $i-j$ indicates any pair of surface elements, with $i, j \in$ $(1,2, \cdots, N)$. In light of the conclusions derived from Table D.1, it was deemed judicious to verify that the view factors computed by Siemens NX 8.5/TMG satisfied Equation (D.5). The numerically calculated values between all elements in the mesh were summed and the resulting deviation from unity was computed as follows:

$$
\Delta F=a b s\left[1-\left(\sum_{j=1}^{N} F_{i-j}\right)\right]
$$

Evaluating Equation (D.6) for $i, j \in(1,2, \cdots, N)$ yielded a maximum deviation of $\Delta F_{\text {Max }}=0.0097$. This negligibly small result suggested that only a miniscule amount of the emitted and reflected radiation will pass through the top and bottom inner liner openings to the surroundings. In turn, this meant that the liner closely approximated an enclosure of the fuel assembly and flow tube. Therefore, it is plausible that numerical solution of Equation (2.24) by VrSuite accurately simulated thermal radiation heat exchange in the fuel channel. 


\section{Appendix E}

\section{Siemens NX 8.5/TMG Verification}

\section{E.1 Numerical Solution}

Verification of the Siemens NX 8.5/TMG FEM software was performed on a long, rectangular enclosure with the dimensions illustrated in Figure E.1:

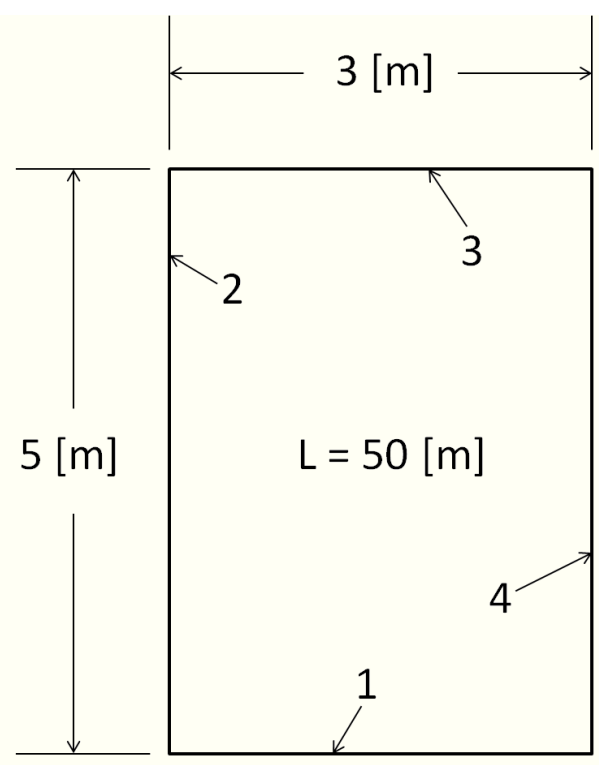

Figure E.1: Long rectangular enclosure used to verify the view factors derived from the Siemens NX 8.5/TMG FEM analyses.

An enclosure length of $\mathrm{L}=50 \mathrm{~m}$ was utilized to simulate the semi-infinite geometry of the analytical model. This measure was taken to ensure that a negligible proportion 
of the radiant energy emitted by the four surfaces would pass through the open ends of the box. In conjunction with the geometry illustrated in Figure E.1, the view factors between the four surface elements were computed numerically via the hemicube method [25][26].

\section{E.2 Analytical Solution}

View factors between the four surfaces comprising the rectangular enclosure in Figure E.1 were computed analytically in reference [24]. However, it warrants mentioning that the quantities derived from Howell, et al. were calculated for an infinitely long box in contrast with the $\mathrm{L}=50 \mathrm{~m}$ geometry presented in the previous section.

\section{E.3 Results}

The numerically and analytically derived view factors between the four enclosure surfaces have been tabulated in the matrices below. A format of $F_{i-j}$ has been utilized, with the subscripts $i$ and $j$ designating the source and target surface numbers, respectively, as illustrated in Figure E.1. For the sake of example, the view factor between source element 3 and target element $4\left(F_{3-4}\right)$ would be located in row 3 and column 4 of the respective numerical $\left(F^{N}\right)$ and analytical $\left(F^{A}\right)$ view factor matrices:

$$
F_{i-j}^{N}=\left[\begin{array}{cccc}
0 & 0.3514 & 0.2589 & 0.3514 \\
0.2108 & 0 & 0.2108 & 0.5421 \\
0.2589 & 0.3514 & 0 & 0.3514 \\
0.2108 & 0.5421 & 0.2108 & 0
\end{array}\right]
$$




$$
F_{i-j}^{A}=\left[\begin{array}{cccc}
0 & 0.3615 & 0.2770 & 0.3615 \\
0.2169 & 0 & 0.2169 & 0.5662 \\
0.2770 & 0.3615 & 0 & 0.3615 \\
0.2169 & 0.5662 & 0.2169 & 0
\end{array}\right]
$$

The results presented above may be more concisely reported by way of a single matrix of percent differences as seen below:

$$
\% \operatorname{Diff}=\left[\begin{array}{cccc}
0 & 2.7939 & 6.5343 & 2.7939 \\
2.8124 & 0 & 2.8124 & 4.2564 \\
6.5343 & 2.7939 & 0 & 2.7939 \\
2.8124 & 4.2564 & 2.8124 & 0
\end{array}\right]
$$

It is evident from the data portrayed above that the numerically and analytically determined view factors agree sufficiently well. Furthermore, it is conceivable that more accurate results would be generated as the enclosure length modelled in Siemens NX 8.5/TMG approaches infinity as it does in the analytical solution. However, this conjecture was not examined due to time constraints. Nevertheless, it may be postulated that the agreement between results observed for this test case may be extended to the fuel channel model studied prior. 


\section{Appendix F}

\section{Fuel Channel Design Optimization}

Section 4.2 Future Work addressed the need for an optimization study to be performed on the liner tube, insulator, and pressure tube dimensions. The first requirement for such a design optimization would be to select a set of lower and upper bounds encompassing the reference dimensions for each design variable depicted in Table 2.1 (note that the flow tube and fuel bundle dimensions are currently constrained by the governing nuclear physics, and thus would not be design variables). For instance:

Table F.1: Lower and upper dimensional bounds for design variables that may be used for optimization of the fuel channel.

\begin{tabular}{|c|c|c|}
\hline $\begin{array}{c}\text { Fuel Channel } \\
\text { Component }\end{array}$ & $\begin{array}{c}\text { Lower Bound on } \\
\text { Thickness }(\mathrm{mm})\end{array}$ & $\begin{array}{c}\text { Upper Bound on } \\
\text { Thickness }(\mathrm{mm})\end{array}$ \\
\hline Inner Liner & 0.5 & 1.0 \\
\hline Gap One & 0.0 & 0.5 \\
\hline Insulator & 0.4 & 8.0 \\
\hline Gap Two & 0.0 & 0.5 \\
\hline Outer Liner & 0.3 & 0.5 \\
\hline Gap Three & 0.5 & 2.0 \\
\hline Pressure Tube & 10.0 & 12.0 \\
\hline
\end{tabular}


In conjunction with the reference dimensions displayed in Table 2.1, the bounds depicted above may be utilized to construct a DOE (Design of Experiments) matrix. Starting with these preliminary fuel channel designs, Gaussian process regression (or Kriging) [28][29] would be employed to generate additional designs. Below are the details of Gaussian process regression as it applies to the investigation at hand, whereas a more general treatment may be found in the referenced literature:

1. An initial DOE matrix is assembled from the reference dimensions and bounds presented in Tables 2.1 and F.1, respectively.

2. Coupled thermal/stress FEM simulations are performed for each of the designs in the initial DOE matrix. The merit of each design is measured by an objective function (described below).

3. A user-specified number $(N)$ of additional fuel channel designs are generated via Gaussian process regression. These new designs are generated such that global uncertainty in the objective function is minimized.

4. Coupled FEM simulations are performed for each of the $N$ new fuel channel designs generated in step 3 .

5. Steps 3 and 4 are repeated for a user-specified number $(M)$ of Kriging iterations, ultimately resulting in $N \times M$ statistically generated fuel channel designs.

The objective of the procedure described above would be to determine the fuel channel design which minimizes an objective function. As was mentioned previously, further research is required to ascertain an effective objective function that quantifies the merit of such fuel channel designs. 


\section{Appendix G}

\section{VrSuite Verification - Optimization Tool}

\section{G.1 Numerical Solution}

An open-ended, internally pressurized tube ${ }^{6}$ was utilized in order to verify VrSuite's optimization feature. A screencapture illustrating the reference geometry and boundary conditions may be found in Figure G.1:

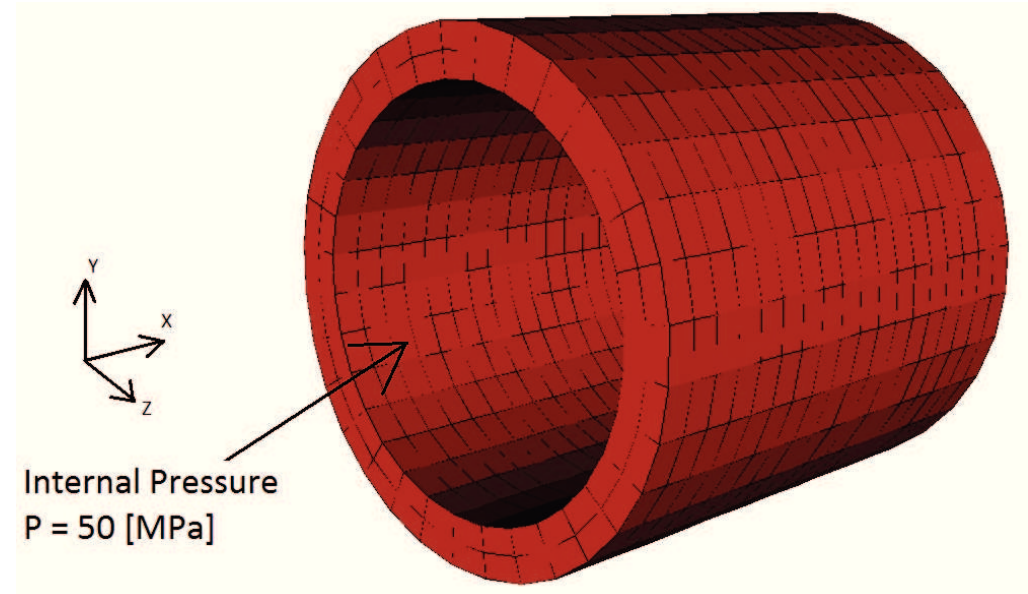

Figure G.1: Reference geometry and mesh with dimensions of $0.4 \mathrm{~m}$ inner radius, $0.5 \mathrm{~m}$ outer radius, and $1.0 \mathrm{~m}$ length. Not shown are the nodal constraints placed upon the $\mathrm{X}, \mathrm{Y}$, and $\mathrm{Z}=0$ planes intended to enforce symmetry and restrain rigid-body motion.

\footnotetext{
${ }^{6}$ Note that the test problem described in this appendix was selected arbitrarily and is unrelated to the analysis of the Canadian SCWR detailed prior.
} 
Starting with the reference geometry depicted above, the outer radius of the tube was permitted to vary (with all other dimensions remaining constant) with the goal of identifying the optimum dimension that minimized the following objective function:

$$
\kappa=\left(\sigma_{V M}-\delta S_{y}\right)^{2}
$$

In other words, an optimum outer radius, $r_{o}^{*}$, was sought that minimized the square of the difference between the global maximum Von Mises and scaled yield stresses. $\delta$ and $\mathrm{S}_{y}$ were arbitrarily set at 0.8 and $3.4 \times 10^{8} \mathrm{~Pa}$, respectively.

In order to identify $r_{o}^{*}$, a set of user-inputs were required to VrSuite's optimization tool. These parameters have been enumerated below:

- Lower bound on $r_{o}: 0.41 \mathrm{~m}$.

- Upper bound on $r_{o}: 0.75 \mathrm{~m}$.

- Initial number of tube designs: 5

- Number of Kriging iterations: 5

- Number of designs generated per iteration: 3

To summarize the data presented above, a total of 17 tube designs were simulated ranging between $r_{o}=0.41 \mathrm{~m}$ and $0.75 \mathrm{~m}$. 


\section{G.2 Analytical Solution}

Although the optimum outer radius of the tube, and thus its thickness, were unknown a priori, the equations for thin-walled pressure vessel stresses were assumed to be valid [30]:

$$
\sigma_{\theta}=\frac{p r_{o}}{r_{o}-r_{i}}
$$

The thin-wall assumption also implies that the radial stress, $\sigma_{r}$, is negligible in comparison with that of $\sigma_{\theta}$ [30]. In addition, any stresses in the axial dimension, $\sigma_{a}$, may be negated since the tube is open on both ends.

Neglecting shear stresses since the only load on the tube is a uniform internal pressure, the Von Mises stress may be written as follows:

$$
\sigma_{V M}=\sqrt{\frac{\left(\sigma_{11}-\sigma_{22}\right)^{2}+\left(\sigma_{22}-\sigma_{33}\right)^{2}+\left(\sigma_{33}-\sigma_{11}\right)^{2}}{2}}
$$

Setting $\sigma_{11}=\sigma_{r}=0, \sigma_{22}=\sigma_{\theta}$, and $\sigma_{33}=\sigma_{a}=0$, Equation (G.3) may be reduced to:

$$
\sigma_{V M}=\sigma_{\theta}
$$

Thus, the objective function described by Equation (G.1) may be re-written as follows:

$$
\kappa=\left(\frac{p r_{o}}{r_{o}-r_{i}}-\delta S_{y}\right)^{2}
$$

Wherein the optimum outer tube radius may be computed by taking the first derivative with respect to $r_{o}$ on both sides of Equation (G.5), setting $d \kappa / d r_{o}$ to zero, and solving the ensuing algebraic equation for $r_{o}^{*}$. 


\section{G.3 Results}

VrSuite FEM simulations were performed for each of the five outer radii appearing in the initial design space. The resulting objective function magnitude was plotted for each design as shown in Figure G.2:

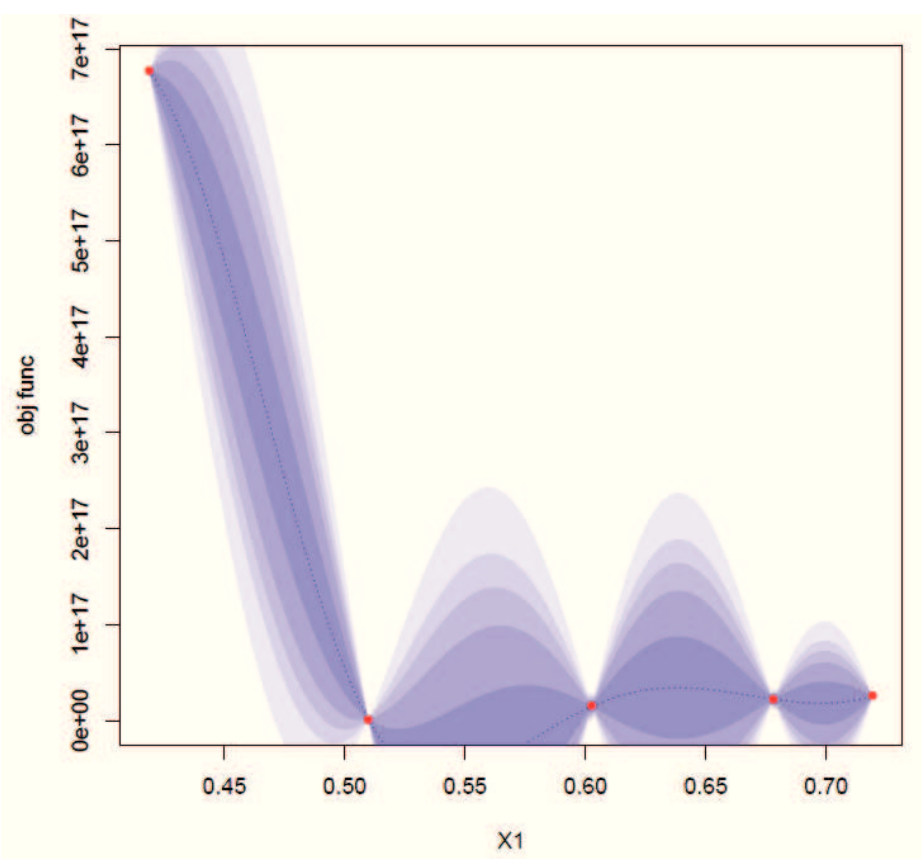

Figure G.2: Objective function magnitude for the five initial tube designs. Also shown are the uncertainty contours in blue.

Twelve additional tube designs were generated over the course of four Kriging iterations, which yielded the results in Figure G.3: 


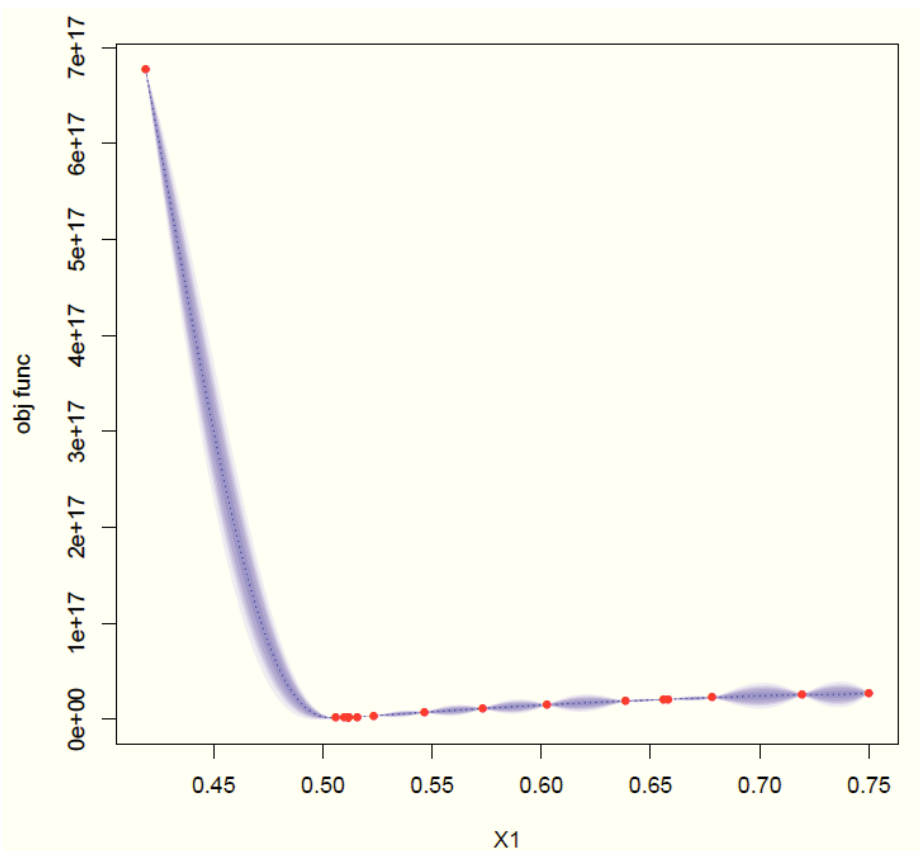

Figure G.3: Objective function magnitude for the final design space, consisting of seventeen outer tube radii. Also shown are the uncertainty contours in blue.

It may be concluded from Figure G.3 that the VrSuite optimization process converged to an outer tube radius of $r_{o, N}^{*}=0.51 \mathrm{~m}$, with a globally minimized objective value of $\gamma=9.96 \times 10^{14} \mathrm{~Pa}^{2}$. This numerical result elicited strong agreement with the analytically derived optimum radius of $r_{o, A}^{*}=0.49 \mathrm{~m}$, with a percent difference of $3.22 \%$. It is tenable that the accuracy of this test problem may be extended to any future dimensional optimization of the fuel channel components. 